\title{
La potestad sancionadora de la Administración financiera
}

\author{
Luis Carlos Fernández-Espinar ${ }^{1}$
}

Sumario: I. INTRODUCCIÓN. II. EL PROCEDIMIENTO SANCIONADOR APLICABLE A LOS SUJETOS QUE ACTUAN EN LOS MERCADOS FINANCIEROS. 1. EI Real Decreto 2119/1993 de 3 de diciembre. A) Ámbito de aplicación. B) Características principales. 2. Las facultades de Supervisión del Banco de España. A) Normativa legal de atribución de competencias. B) El ejercicio de las facultades de supervisión del Banco de España. C) El ejercicio de la potestad sancionadora del Banco de España. a) Tramitación de expedientes sancionadores. b) Resolución de expedientes sancionadores. c) Tipos de Sanciones. III. EL MARCO LEGAL REGULADOR DE LOS MERCADOS FINANCIEROS. 1. Normativa relativa a la ordenación de la actividad interna y del capital. 2. Normativa relativa a la ordenación de la actividad externa de las entidades y su clientela. IV. EL CONTENIDO MATERIAL DEL REGIMEN SANCIONADOR DE LAS ENTIDADES DE CREDITO REGULADO EN LA LEY 26/1988 DE DISCIPLINA E INTERVENCIÓN. 1. Características generales. 2. Infracciones. A) Infracciones muy graves. B) Infracciones graves. C) Infracciones leves. D) Prescripción de infracciones. 3. Sanciones. A) Entidades. B) Cargos de Administración y Dirección. 4. Medidas de Intervención y Sustitución.

\section{INTRODUCCIÓN}

La aprobación de la Ley 30/1992 de 26 de noviembre, sobre Régimen Jurídico de las Administraciones Públicas y el Procedimiento Administrativo Común, que dedicó el Título IX a la regulación del régimen jurídico de la potestad sancionadora, hizo necesario adecuar la regulación de todos los procedimientos sancionadores a sus previsiones. El capítulo II del citado Título IX no contiene realmente una regulación de un procedimiento sancionador sino unos principios que deben inspirar las distintas regulaciones sectoriales y la actuación de las Administraciones Publicas de conformidad con lo dispuesto en el artículo 134.1. Con esta regulación, la Ley 30/1992 se separa de la Ley de Procedimiento Administrativo de 1958 que, a diferencia de ella, sí contenía

1 Profesor Titular de Derecho Administrativo. Universidad Politécnica de Madrid. 
en su Título VI dedicado a los procedimientos especiales una regulación de un procedimiento sancionador mediante una serie de trámites debidamente ordenados y relacionados entre sí.

En el ámbito de la disciplina de las entidades financieras y, por extensión, en el de la disciplina de los mercados financieros, la pluralidad y elevado número de disposiciones aplicables suele incluir un amplio cuadro normativo de infracciones y sanciones adoleciendo de una regulación de un procedimiento sancionador completo hasta la aprobación del Real Decreto 2119/1993 de 3 de diciembre que regula el Procedimiento sancionador aplicable a los sujetos que actúan en los mercados financieros (B.O.E. 23.XII, 1993).

Con anterioridad a la aprobación del Real Decreto 2119/1993 de 3 de diciembre, la normativa reguladora de los mercados financieros optó por remitirse en el ámbito sancionador a la Ley de Procedimiento Administrativo de 1958, si bien en numerosos casos el reenvío normativo no era directo sino que se hacía mediante la remisión a la Ley $26 / 1988$, de 29 de julio, sobre disciplina e intervención de las entidades de crédito, que a su vez se remitía a la Ley rituaria mencionada de 1958. La disposición derogatoria de la Ley 30/1992 derogó expresamente, como es bien conocido, el capítulo II del Título VI de la Ley de 1958, por lo que con ello dejó de existir un procedimiento sancionador específico para el sector financiero, siendo totalmente necesario la aprobación de una norma que regulara con detalle las especialidades de dicho procedimiento ajustándose a los principios y directrices recogidos en la nueva Ley 30/1992.

Y todo ello sin perjuicio de que cuatro meses antes, en agosto del mismo año 1993, se aprobara el Real Decreto 1398/1993 relativo al Reglamento del Procedimiento general para el ejercicio de la potestad sancionadora cuyo carácter general le impide tratar adecuadamente las importantes singularidades que se dan en la instrucción de los procedimientos sancionadores en los que los inculpados son sujetos que actúan en los mercados financieros. El propio Real Decreto 1398/1993 establece en su artículo 1. ${ }^{\circ}$ que "la potestad sancionadora se ejercerá mediante el procedimiento establecido en este Reglamento, en defecto total o parcial de procedimientos específicos previstos en las correspondientes normas".

No obstante la citada previsión, y con buen criterio de coherencia y uniformidad normativa, el Real Decreto 2119/1993, de 3 de diciembre, establece en su artículo 1.3 el carácter supletorio del Reglamento general para el ejercicio de la potestad sancionadora, regulando en su contenido las especialidades justificadas por la complejidad del sector financiero, siendo en lo demás aplicable la normativa común.

En el presente trabajo expondremos la regulación material y formal de la potestad sancionadora de la Administración en el ámbito de las entidades financieras y en general de los mercados financieros, teniendo en cuenta la abundante normativa sectorial sobre la materia cuya continua modificación y además enorme complejidad téc242 nica son características singulares y específicas de la misma. La Jurisprudencia, el Tri- 
bunal Supremo y la Audiencia Nacional, han tenido ocasión en los últimos años de fijar la doctrina sobre la legalidad del ejercicio de la potestad sancionadora en las numerosas infracciones que sobre esta materia se establecen en la diversa legislación sectorial reguladora de los mercados financieros.

Los recientes acontecimientos internacionales y nacionales, y la consiguiente crisis del sector financiero con sus enormes repercusiones para todos los ciudadanos en su vida diaria, hacen de este ámbito regulador y de supervisión de la Administración Pública uno de los más necesarios en el ineludible ejercicio de la responsabilidad de supervisión y potestad sancionadora de las Administraciones Públicas.

La enorme amplitud del ámbito financiero y del mercado de capitales nos obliga en el presente trabajo, por razones de límite de páginas, a centrar el objeto del mismo en los aspectos principales y en los caracteres específicos en este ámbito de la potestad sancionadora de la Administración, con el análisis detallado, en primer lugar, del Real Decreto 2119/1993 de 3 de diciembre que regula el procedimiento sancionador específico en este ámbito, y, en segundo lugar, de la Ley 26/1988 de 29 de julio sobre Disciplina e Intervención de las Entidades de Crédito (LDIEC) que constituye la norma de carácter sancionador más importante en el ámbito financiero tanto por su contenido material sancionador como por los sujetos que entran dentro de su ámbito de aplicación y que son las Entidades de crédito así como otras instituciones financieras que desarrollan esencialmente ese tipo de actuaciones y actividades.

Por otra parte, un número importante de Leyes de carácter financiero, como citamos más adelante, establecen que será de aplicación en su ámbito correspondiente el régimen sancionador establecido en el Título I de la Ley 26/1988 de 29 de julio sobre Disciplina e Intervención de las Entidades de Crédito, artículos 1 a 27 de la misma, con su listado específico de infracciones y sanciones. Incluso, la propia Ley 24/1988 del Mercado de Valores, que establece en sus artículos 99 a 101 una abundante lista de infracciones, establece en el ejercicio del procedimiento sancionador competencia de la CNMV una remisión expresa, en su artículo 98.1, al contenido de los artículos 7, 14, 15 y 17 de la Ley 26/1988, así como, en su artículo 107, la aplicación igualmente de las Medidas de intervención y sustitución reguladas en el Título III de la misma.

Todo ello, nos obliga a dedicar un apartado del presente trabajo a exponer el marco legal actualizado regulador de los mercados financieros con el carácter más amplio posible tanto desde la vertiente interna de la actividad financiera -organización, financiación y solvencia de las empresas de servicios financieros, entidades de crédito y aseguradoras-, como en el aspecto externo de la misma es decir en las relaciones entre los sujetos que operan en los mercados financieros y su clientela².

2 Sobre el marco legal regulador de los mercados financieros, puede consultarse la siguiente selección de Bibliografía: Bassols Coma, M. “Constitución y sistema económico”, Ed. Tecnos, Madrid, 1988. Carrasco Canals, C. "El Banco de España y las Cajas de Ahorro”, R.A.P. n. ${ }^{124}$, enero-abril 1991, pp. $149-209$. 


\title{
II. EL PROCEDIMIENTO SANCIONADOR APLICABLE A LOS SUJETOS QUE ACTUAN EN LOS MERCADOS FINANCIEROS
}

\author{
1. El Real Decreto $2119 / 1993$ de 3 de diciembre
}

Como hemos comentado, el Real Decreto 2119/1993 de 3 de diciembre establece el procedimiento sancionador específico aplicable a los sujetos que actúan en los mercados financieros.

\section{A) Ámbito de aplicación}

El ámbito de aplicación del presente Real Decreto se establece en su artículo 1., mediante la técnica de referir el objeto del mismo a la regulación de las especialidades del procedimiento sancionador atribuidas a diversas disposiciones normativas que inicialmente en 1993 eran las siguientes:

1. Ley $24 / 1988$, de 28 de julio, del mercado de valores.

2. Ley $26 / 1988$, de 29 de julio, sobre disciplina e intervención de las entidades de crédito.

\begin{abstract}
Casares Marcos, A.B. “La unidad de régimen jurídico de las Cajas de Ahorros: las Cajas de fundación eclesiástica”, R.A.P. n. ${ }^{161}$, mayo-agosto 2003, pp. 395-433. Cosculluela Muntaner, L. y López Benítez, M. “De-

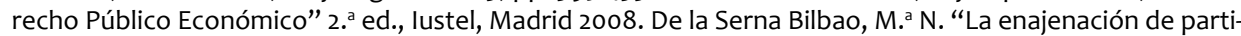
cipaciones públicas en empresas que realizan actividades de interés público. Su regulación por la Ley 5/1995, de 23 de marzo”. R.A.P. n. 143, mayo-agosto 1997, pp. 435y 461, Madrid. Del Guayo Castiella, I. "Estudio de la nueva Corporación Bancaria de España S.A. particularmente a la luz del Derecho comunitario europeo, R.D.B.y B., n. ${ }^{\circ}$ 44, 1991, pp. 939 y ss. Fernández Rodríguez, T.R. "Comentarios a la Ley de Disciplina e Intervención de las Entidades de Crédito", Estudio Preliminar, en Estudios de la Obra Social de la Confederación Española de Cajas de Ahorros, pp. 9 y ss, Madrid 1989. Jiménez-Blanco, A. "Comentarios a la Ley de Disciplina e Intervención de las Entidades de Crédito”, en Estudios de la Obra Social..., pp. 140 y ss, Madrid 1989. Fuertes, M. “Mercado Único de Valores y Comunidades Autónomas (Comentario a la Sentencia del Tribunal Constitucional 133/1997, de 16 de julio)”, R.A.P. n. ${ }^{145}$, enero-abril 1998, pp. 147-167, Madrid. Martín-Retortillo Baquer, S. “Estudios de Derecho Público Bancario”. Ed. Ceura, Madrid 1987. Martín-Retortillo Baquer, S. “Reflexiones sobre la Ley de Disciplina e Intervención Bancaria”,R.A.P n. `118, 1989, págs 7-34. Martín-Retortillo Baquer, S. “Derecho administrativo económico”. Ed. La Ley, Madrid 1991. Martín-Retortillo Baquer, L. “Las sanciones administrativas en relación con la defensa de los consumidores con especial referencia a la publicidad de las mismas”, R.A.P. n. ${ }^{\circ}$ 126, septiembre-diciembre 1991, pp. $133-187$. Pascua Mateo, F. "las nuevas Leyes de estabilidad presupuestaria: aspectos formales y materiales”, R.A.P. n. ${ }^{\circ}$ 158, mayo-agosto 2002, pp. 119-185, Piñar Mañas, J.L. "Comentarios a la Ley de Disciplina e Intervención de las Entidades de Crédito", en Estudios de la Obra Social de la Confederación Española de Cajas de Ahorros, pp. 69 y ss, Madrid 1989. Ponce Solé, J. “La evolución de la actividad pública en el sector financiero: Las transformaciones de la Entidad de crédito "Corporación Bancaria de España, Sociedad anónima", R.A.P. n. ${ }^{\circ}$ 146, mayo-agosto 1998, pp. 389-418. Prieto Álvarez, T. “Las Cajas de Ahorro francesas cambian su estatuto jurídico (Elementos de reflexión para el caso español)”, R.A.P. n. ${ }^{155}$, mayo-agosto 2001, pp. 417431. Soriano García, J.E.”'Las competencias del Estado y de las Comunidades Autónomas sobre el mercado 244 de capitales", R.A.P. n. ${ }^{\circ}$ 115, enero-abril 1988, pp. 167-202. Villar Palasi, J.L."Medidas de intervención y de sustitución".
\end{abstract}


3. Ley 46/1984, de 26 de diciembre, de instituciones de inversión colectiva. Esta Ley ha sido derogada por la Ley 35/2003 de 4 de noviembre que regula en la actualidad esta materia.

4. Ley 33/1984, de 2 de agosto, sobre ordenación del seguro privado, que ha sido derogada por el vigente Texto Refundido aprobado mediante el RD Legislativo $6 / 2004$, de 29 de octubre.

5. Ley 9/1992, de 30 de abril, de mediación en seguros privados, que ha sido derogada por la vigente Ley $26 / 2006$, de 17 de julio de mediación de seguros y reaseguros privados.

6. Ley $8 / 1987$, de 8 de junio, de regulación de los planes y fondos de pensiones, que ha sido derogada por el vigente Real Decreto Legislativo 1/2002 de 29 de noviembre.

7. El artículo 89 del Real Decreto Legislativo 1564/1989, de 22 de diciembre por el que se aprueba el Texto refundido de la Ley de Sociedades Anónimas, y que establece el régimen sancionador en relación con "los negocios sobre las propias acciones" por parte de dichas sociedades, regulado en la sección IV del Capítulo IV relativo a "las acciones". Este artículo 89 establece lo siguiente:

\section{“Artículo 89. Régimen sancionador}

3. Son responsables de la infracción los administradores de la sociedad infractora y, en su caso, los de la sociedad dominante que hayan inducido a cometer la infracción. Se consideran administradores no sólo los miembros del Consejo de administración sino también los directivos o personas con poder de representación de la sociedad infractora. La responsabilidad se exigirá conforme a los artículos 127 y 133 de la presente Ley.

4. Las infracciones y las sanciones prescribirán a los tres años, computándose de acuerdo a lo dispuesto en el artículo 132 de la Ley 30/1992.

5. La competencia para la iniciación, instrucción y resolución de los expedientes sancionadores se atribuye a la Comisión Nacional del Mercado de Valores. En el caso de que el expediente recaiga sobre los administradores de una entidad de crédito, de una entidad aseguradora o sobe una entidad integrada en un grupo consolidable de entidades financieras sujeto a la supervisión del Banco de España o de la Dirección General de Seguros, la Comisión Nacional del Mercado de Valores comunicará a las mencionadas entidades de supervisión la apertura de expediente, las cuales deberán también informar con carácter previo a la resolución. (Redactado conforme a la Disposición Adicional 2 de la Ley 2/1995, de 23 de marzo)."

8. El artículo 20 del Real Decreto-Ley $1 / 1986$, de 14 de marzo, en materia de entidades de capital riesgo, que ha sido derogado y sustituido por la Ley 1/1999, de 5 de enero, reguladora de las Entidades de capital riesgo y de sus sociedades gestoras. 
9. El Real Decreto $1885 / 1978$, de 26 de julio sobre régimen jurídico fiscal y financiero de Sociedades de Garantía Recíproca que ha sido derogado por la vigente Ley 1/1994, de 11 de marzo sobre Régimen jurídico de las Sociedades de Garantía Recíproca.

Respecto de la aplicación del Real Decreto 2119/1993, deben tenerse en cuenta, además, las siguientes normas donde existe una remisión a la aplicación de su procedimiento sancionador en las siguientes materias: control de cambios (Real Decreto 1392/1993, de 4 de agosto), cambio de moneda extranjera en establecimientos abiertos al público distintos de las entidades de crédito (Real Decreto 2660/1998, de 14 de diciembre), régimen jurídico de homologación de los servicios y sociedades de tasación (Real Decreto 775/1997 de 30 de mayo), y prevención del blanqueo de capitales (Real Decreto 925/1995 de 9 de junio).

Por otra parte, otras normas de carácter financiero establecen que será de aplicación en su ámbito correspondiente el régimen sancionador establecido en el Título I de la LDIEC, artículos 1 a 27 de la misma, con su listado específico de infracciones y sanciones. Así lo establecen la Ley 13/1996 de 30 de diciembre, de medidas fiscales, administrativas y del orden social en su artículo 178 en relación con el régimen sancionador aplicable a los titulares de establecimientos de cambio de moneda; la Ley 13/1989, de 26 de mayo, de Cooperativas de Crédito en su artículo 12, y su Reglamento de desarrollo aprobado por Real Decreto 84/1993, de 22 de enero, en sus artículos 27.4 y 38, relativos respectivamente, de una parte, a la destitución, suspensión o separación de los Directores de las mismas, y, de otra, a las sanciones a las cooperativas en general; e igualmente la Ley 1/1994, de 11 de marzo, de régimen jurídico de las Sociedades de Garantía Recíproca, en su artículo 67, que aplica el citado régimen sancionador tanto a dichas sociedades de garantía recíproca y a las sociedades de reafianzamiento, como a quienes ostenten cargos de administración o dirección en las mismas.

\section{B) Características principales}

La regulación contenida en esta norma se caracteriza por los siguientes características principales:

a) En primer lugar, se tienen en cuenta, como no podía ser menos, los derechos y garantías del expedientado dándole la posibilidad de utilización de todos los medios de defensa que estime pertinentes. En algunos aspectos, es incluso más garantista que la regulación contenida en el Reglamento de aplicación general, como demuestra la existencia de plazos más amplios -veinte días a diferencia de los quince del régimen general en la contestación al pliego de cargos y en el trámite de audiencia para la formulación de alegaciones ante la propuesta de resolución-, así como la imposibilidad de prescindir de este trámite de audiencia a diferencia de la existencia de esta posibi-

246 lidad en el régimen general que establece el artículo 19.2 del Real Decreto 1398/1993. 
b) En segundo lugar, se pretende facilitar que el instructor, a lo largo de los sucesivos trámites y guardando la debida confidencialidad, pueda llegar a una perfecta determinación de los hechos que motivan la apertura del procedimiento. La complejidad técnica existente en estos procedimientos justifica el posible nombramiento de instructores o secretarios adjuntos según establece el artículo $4 .^{\circ}$, y entre las facultades del instructor expresamente se establece en el artículo $5 .^{\circ}$ que el mismo podrá solicitar cuantos informes técnicos o jurídicos sean necesarios atendiendo a la complejidad de la materia.

En relación con esta cuestión, merece destacarse la Sentencia del Tribunal Supremo de 18 de octubre de 2006 (TOL 1.009.688) en relación con el Acuerdo sancionador del Consejo de Ministros a la entidad "Eurobank del Mediterráneo" y a sus cargos con imposición de cuatro sanciones de revocación de la autorización de la entidad en relación con cuatro infracciones muy graves del artículo 4 de la LDIEC. En lo que aquí ahora nos interesa, la demandante alega infracción del artículo 62.1e) de la Ley 30/1992 en relación con el artículo 22 de la Ley 26/1988 y artículos 4 y 6 del Real Decreto 2119/1993 con el motivo que "a partir de un determinado momento de la instrucción, todos los escritos y acuerdos fueron firmados por el instructor adjunto, sin que volviera a aparecer ya el designado inicialmente como instructor del expediente". La Sentencia rechaza esta alegación estableciendo que la posibilidad de nombramiento de instructores adjuntos permite que a partir de dicho nombramiento sea el instructor adjunto quien firme todas las diligencias y actuaciones del procedimiento sancionador, incluso la formulación del propio pliego de cargos bajo la dirección del instructor principal:

"El alegato ha de ser rechazado pues ni ha habido infracción del procedimiento ni, en ningún caso, se le ha ocasionado a la actora indefensión. Así, la posibilidad de designar instructores adjuntos está reconocida, como admite la propia actora, en la misma LDIEC, en su artículo 22, así como en el Real Decreto 2119/1993, de 3 de diciembre, sobre el procedimiento sancionador aplicable a los sujetos que actúan en los mercados financieros (artículo 4). Pues bien, reconocida legalmente dicha posibilidad y nombrado un instructor adjunto en un determinado procedimiento, ningún obstáculo hay para que el mismo actúe a partir de ese momento firmando cuantas diligencias sean procedentes, incluso la formulación del pliego de cargos, bajo la dirección del instructor principal. A este respecto y como pone de relieve el Abogado del estado, el artículo 6 del citado Real Decreto 2119/1993 únicamente señala que el pliego de cargos ha de ser formulado por el instructor, sin que exija expresamente ni pueda entenderse implícito que dicho instructor ha de ser necesariamente el instructor principal".

c) En tercer lugar, la regulación adoptada es en consecuencia más compleja, por todo lo manifestado, manteniendo la figura del pliego de cargos en el artículo $6 .^{\circ}$, que deberá incluir el siguiente contenido específico: 1.Diligencias practicadas hasta el momento de su formulación. 2. Concreción de los hechos imputados a cada presunto responsable. 3. Tipificación de la infracción. 4. Sanciones que se podrían imponer. 5. Autoridad competente para imponer la sanción o sanciones, y norma que atribuya tal competencia. 
En relación con el pliego de cargos, el contenido del acuerdo de iniciación establecido en el artículo $3 .^{\circ}$ varía con respecto al regulado en el régimen general en el artículo 13.1 del Real Decreto 1398/1993, existiendo dos excepciones con respecto a éste. En primer lugar, la calificación de los hechos que motivan la incoación del procedimiento y la determinación de las sanciones que pudieran corresponder se diferirán al pliego de cargos. Y, en segundo lugar, no será de aplicación lo dispuesto en el párrafo d) en cuanto a la posibilidad de que el presunto responsable pueda reconocer voluntariamente su responsabilidad con los efectos previstos en el artículo 8 del Real Decreto 1398/1993, relativos a la posibilidad de aplicar reducciones sobre el importe de la sanción pecuniaria propuesta.

d) En cuarto lugar, el plazo total para tramitar y resolver el procedimiento sancionador es más largo del existente en el régimen general, siendo de un año a contar desde la adopción del acuerdo de iniciación, de conformidad con lo establecido en el artículo 2.1, frente a los seis meses que recoge el artículo 20.6 del Reglamento general 1398/1993, de 4 de agosto. Igualmente, se prevé un procedimiento simplificado en el artículo 10 cuyo plazo de resolución es de cuatro meses frente al plazo de un mes que se establece en el régimen general del Real Decreto 1398/1993. Para todos los plazos, tanto el total de resolución, como los parciales previstos en el Real Decreto 2119/1993, el artículo 2.2 establece que los mismos podrán ser ampliados según lo dispuesto en el artículo 49.1de la Ley 30/1992, debiéndose notificar la decisión a los interesados.

El procedimiento simplificado no sólo podrá seguirse en relación con las infracciones leves como en el caso del Reglamento del régimen general, sino también, y a diferencia de lo dispuesto en aquél, para las infracciones graves cuando, según se establece en el artículo 10, los hechos estén claramente determinados por haberse probado en otras actuaciones sancionadoras o consignado en actas de inspección, por haberse reconocido o declarado por los propios interesados, o bien por constar en registros administrativos o por otras circunstancias justificadas.

En relación con el procedimiento simplificado, el Real Decreto 2119/1993 establece dos cuestiones específicas con respecto al régimen general. En primer lugar, notificado el acuerdo de iniciación el instructor tendrá un plazo de un mes para la práctica de actuaciones y la determinación de las responsabilidades susceptibles de sanción durante el cual los interesados podrán formular alegaciones y aportar documentos. En el régimen general este plazo es de diez días. Y, en segundo lugar, el instructor a la vista de las actuaciones podrá plantear bien que se siga el procedimiento general en razón de la complejidad o de la naturaleza de las infracciones, o bien formular propuesta de resolución. En este segundo caso, los interesados podrán formular en el plazo de diez días las alegaciones y presentar los documentos que estimen pertinentes. Recibidas las mismas, el instructor elevará la propuesta junto con las alega248 desde la recepción de las alegaciones. 
En el Reglamento general aprobado mediante el Real Decreto 1398/1993, no se contempla el trámite de alegaciones frente a la propuesta de resolución, elevando directamente el instructor su propuesta al órgano competente para que en el plazo de tres días dicte resolución.

e) En quinto lugar, el Real Decreto 2119/1993 sobre procedimiento sancionador de los mercados financieros, regula en el artículo 5.2 lo relativo a las medidas provisionales que se pueden acordar, así como diversas cuestiones sobre la Resolución en su artículo 9. En relación con las medidas provisionales que pueden adoptar el órgano que acuerda la iniciación del procedimiento, se establece que podrán ser las específicamente previstas en las disposiciones normativas citadas en su artículo $10^{\circ}$ así como las que se estimen necesarias para asegurar la eficacia de la resolución final según establece en el artículo 15 del Reglamento general para el ejercicio de la potestad sancionadora 1398/1993. A diferencia de lo que se establece en el Reglamento general, el Real Decreto 2119/1993 establece en su artículo 5.2 que el órgano competente para adoptar las medidas provisionales podrá disponer la publicación de las mismas, según lo dispuesto en el artículo 60 de la Ley 30/1992, así como su inscripción en los Registros públicos correspondientes, especialmente en el caso que el obligado no las cumpla voluntariamente.

Y, en relación con lo dispuesto en el artículo 9 sobre la Resolución, el Real Decreto $2119 / 1993$ establece la posibilidad de acordar actuaciones complementarias que serán practicadas por el instructor dando audiencia a los interesados de su resultado por siete días. A diferencia del régimen general, artículo 20.1, en este procedimiento especial no se contempla plazo de alegaciones de los interesados en relación con el propio acuerdo de realización de actuaciones complementarias sino en relación con su resultado. Por otra parte, mientras que el plazo para dictar la Resolución definitiva es de diez días en el procedimiento general, en este procedimiento sancionador especial el plazo es de tres meses a contar desde la recepción de las últimas alegaciones de los interesados o desde la finalización del plazo de veinte días del trámite de audiencia, regulada en el artículo 8.

f) Finalmente, el Real Decreto 2119/1993 establece en tres Disposiciones Adicionales determinadas cuestiones relativas a los seguros privados (Disposición Adicional 1. ${ }^{a}$ ), a la competencia de la Comisión Nacional del Mercado de Valores (Disposición Adicional $2 .^{\mathrm{a}}$ ), y a la aplicación supletoria a los procedimientos sancionadores cuya competencia esté atribuida a las Comunidades Autónomas según su legislación específica (Disposición Adicional 3. ${ }^{a}$ ).

En el ámbito de la ordenación de los seguros privados, la Disposición Adicional primera establece que tendrá el carácter de actuación previa, a los efectos del artículo 12 del Real Decreto 1398/1993 regulador del régimen general, la tramitación que se efectúe como consecuencia de las comunicaciones formuladas por los asegurados sin perjuicio de la publicidad que deba darse a las resoluciones que pongan término a tales procedimientos. 
En cuanto a la CNMV, la D.A. 2. ${ }^{\text {a }}$ le otorga la competencia para incoar los procedimientos sancionadores respecto de los que las normas citadas en el artículo 1. $\mathrm{de}$ este Real Decreto le atribuye la competencia para su instrucción, y asimismo se establece que le corresponde a la Comisión Nacional la competencia para incoar e instruir los procedimientos sancionadores por incumplimiento de los previsto en la sección IV "De los negocios sobre las propias acciones", ya citado anteriormente, del T.R. de la Ley de Sociedades Anónimas, aprobado mediante Real Decreto legislativo 1564/1989, de 22 de diciembre.

\section{Las facultades de Supervisión del Banco de España}

\section{A) Normativa legal de atribución de competencias}

Las funciones y facultades de supervisión del Banco de España tienen su fundamento y base legal en diversas normas de carácter financiero y, en primer lugar, en la propia Ley de Autonomía del Banco de España 13/1994, de 1 de junio. En el artículo 7 de la misma se establece las funciones que le corresponden al Banco de España, entre las que se encuentra en su apartado 6 la de supervisión de "la solvencia, actuación y cumplimiento de la normativa específica de las entidades de crédito y de cualesquiera otras entidades y mercados financieros cuya supervisión le haya sido atribuida, sin perjuicio de la función de supervisión prudencial llevada a cabo por las Comunidades Autónomas en el ámbito de sus competencias y de la cooperación de éstas con el Banco en el ejercicio de tales competencias autonómicas de supervisión".

El Banco de España se configura como un Ente de la Administración del Estado de naturaleza especial, sometido con carácter general al ordenamiento jurídico-privado, como establece el artículo 1.2 de dicha Ley, salvo que actúe en el ejercicio de potestades administrativas en cuyo caso le es de aplicación la Ley 30/1992. Precisamente, este artículo 1.2 establece que en cualquier caso tienen naturaleza administrativa los actos que dicte en el ejercicio de las funciones del artículo 7.6 que son las citadas funciones de supervisión, y del artículo 15.4 que le otorga la competencia para otorgar la autorización a las entidades privadas que realicen publicidad utilizando billetes o monedas que tengan o hayan tenido curso legal, así como para imponer sanciones pecuniarias de hasta 600.010 euros por incumplimiento de las condiciones fijadas en la autorización o por no contar con la misma.

En relación con las facultades de supervisión del Banco de España, debe tenerse en cuenta la siguiente normativa financiera sectorial:

a) Ley 26/1988 de Disciplina e Intervención de las Entidades de Crédito, en cuyo artículo 43 bis le otorga amplias facultades de supervisión consistentes en el control e inspección de las entidades de crédito, así como de la aplicación de la Ley 2/1981 sobre Regulación del Mercado Hipotecario. Igualmente, y como actividad de cierre

250 de sus facultades de supervisión, el artículo 18 de esta Ley le otorga la competencia 
para la instrucción de los expedientes sancionadores así como para la imposición de sanciones por faltas graves y leves, correspondiendo al Ministro de Economía y Hacienda, a propuesta del Banco de España, la competencia para las sanciones de faltas muy graves salvo la de revocación de la autorización que corresponde al Consejo de Ministros.

Excepcionalmente, tratándose de establecimientos de cambio de moneda y gestión de transferencias en el exterior, así como en el caso de intrusos en el sector financiero, la competencia para la imposición de las sanciones, cualquiera que sea su graduación, corresponde al Banco de España.

b) Ley 24/1988 del Mercado de Valores, en cuyo artículo 88 párrafo primero redactado según la Ley 44/2002 de 22 de noviembre, establece que el Banco de España ejercerá facultades de supervisión e inspección sobre los miembros del Mercado de Deuda Pública en Anotaciones, los titulares de cuenta a nombre propio y sobre las entidades gestoras, así como sobre las actividades relacionadas con el mercado de valores realizadas por entidades inscritas en los Registros a su cargo, a que se refiere el artículo 65. La Ley fue impugnada ante el Tribunal Constitucional por los Gobiernos vasco y catalán así como por el Parlamento de Cataluña, habiendo resuelto la Sentencia 133/1997, de 16 de julio, los conflictos de competencia suscitados, manteniendo con algún pequeño matiz el sistema implantado.

En todos los casos de concurrencia de competencias de supervisión e inspección entre la CNMV y el Banco de España, según establece el párrafo segundo del artículo 88 redactado según la Ley 47/2007, de 19 de diciembre, ambas instituciones deben coordinar sus actuaciones bajo el principio de que la tutela del funcionamiento de los mercados de valores, incluyendo las cuestiones de organización interna señaladas en el apartado 1 del artículo 70 ter, corresponde a la CNMV, mientras que la tutela de la solvencia así como las restantes cuestiones de organización interna recaen sobre la institución que mantenga el correspondiente registro. Para la adecuada coordinación del ejercicio de dichas competencias, deberán suscribir convenios en los que se concreten sus correspondientes responsabilidades.

En el ámbito de aplicación de la LMV, que son los instrumentos financieros enumerados en su artículo $2 .^{\circ}$-principalmente valores negociables cuya emisión, negociación o comercialización en el territorio nacional, así como contratos de opciones, futuros, permutas y otros instrumentos financieros-, la competencia para la incoación, instrucción y sanción de los procedimientos sancionadores corresponde, en virtud de lo dispuesto en el artículo 97 de la Ley, a la CNMV excepto la imposición de sanciones por faltas muy graves que corresponde al Ministro de Economía y Hacienda, a propuesta de la Comisión Nacional y previo informe de su Comité Consultivo, salvo la de revocación de la autorización que corresponde al Consejo de Ministros.

c) Otras Leyes que otorgan facultades de supervisión al Banco de España son la Ley 13/1985 relativa a los coeficientes de inversión, recursos propios y obligaciones 
de información de los intermediarios financieros, en sus artículos 9.2 y 12.2; la Ley 13/1994 de adaptación de la legislación española en materia de entidades de crédito a la segunda Directiva de Coordinación Bancaria, en su D.A. 10. en relación con las sociedades de tasación; la Ley 1/1994 de 11 de marzo sobre régimen jurídico de las Sociedades de Garantía Recíproca, en su artículo 66; y la Ley 13/1996 relativa a Medidas fiscales, administrativas y del orden social, en su artículo 178 relativo a las casas de cambio de moneda.

\section{B) El ejercicio de las facultades de supervisión del Banco de España}

Corresponde al Banco de España, de conformidad con el artículo 43 bis de la LDIEC como venimos manifestando, el control e inspección de las entidades de crédito extendiéndose esta competencia a cualquier oficina o centro, dentro o fuera del territorio nacional, así como a las sociedades que se integren en el grupo de la afectada en la medida que sea necesario. Igualmente, le corresponde la supervisión de los grupos consolidables de entidades de crédito, según lo dispuesto en la Ley 13/1992 de 1 de junio sobre Recursos propios y supervisión en base consolidada de las Entidades Financieras. Las resoluciones que dicte el Banco de España en el ejercicio de estas funciones serán susceptibles de recurso ante el Ministro de Economía y Hacienda.

Todo ello, y en relación con las competencias de las Comunidades Autónomas, debe entenderse sin perjuicio de lo que resulte de los convenios entre el Banco de España y las Comunidades Autónomas a que se refiere la Disposición adicional primera, apartado $3 .^{\circ}$, de la Ley 31/1985, de 2 de agosto, sobre Órganos Rectores de las Cajas de Ahorros. En todo caso, la inscripción en los correspondientes registros del Banco de España y, cuando proceda, de la Comunidad Autónoma competente es indispensable para que estas entidades puedan desarrollar sus actividades. Corresponde al Banco de España o al Ministro de Economía y Hacienda o al Consejo de Ministros, de conformidad con el artículo 42.2 de la LDIEC, el ejercicio de la potestad sancionadora respecto a las Cajas de Ahorro y las Cooperativas de Crédito cuando se trate de las infracciones establecidas en las letras b), c) y f) del artículo $4 .^{\circ}$ y en las letras g), h), i), k) y p) del artículo 5 de la LDIEC o, en general, de infracciones de normas de carácter monetario o que afecten a la solvencia de las entidades ${ }^{3}$.

Las funciones y actuaciones de supervisión del Banco de España se agrupan en dos apartados, según la Memoria anual de la Supervisión Bancaria en España, relativos, en primer lugar, a Entidades de Crédito, y, en segundo lugar, a Otras entidades. En el primer apartado, se incluyen los Bancos, Cajas de Ahorros, Cooperativas de cré-

3 En relación con el contenido del artículo 42.2 expuesto en el párrafo anterior, debe tenerse en cuenta la Sentencia del Tribunal Constitucional 96/1996, de 30 de mayo, que ha declarado su constitucionalidad interpretada en el sentido expuesto en su fundamento jurídico $7 .^{\circ}$ Sin embargo, esta misma Sentencia declaró la inconstitucionalidad del artículo 42 con los efectos indicados en sus fundamentos jurídi252 respecto de otras entidades de crédito distintas a las Cajas de Ahorros o a las Cooperativas de Crédito. 
dito, Sucursales de entidades de crédito extranjeras, Comunitarias, y Establecimientos financieros de crédito. En el segundo apartado relativo a Otras Entidades figuran las Sociedades de Tasación, Sociedades de Garantía Recíproca, y los Establecimientos de cambio y transferencias ${ }^{4}$.

Como consecuencia de las funciones y actuaciones de supervisión, el ordenamiento jurídico otorga al Banco de España la competencia para la adopción de las siguientes medidas: a) Recomendaciones y requerimientos; b) Aprobación de planes de saneamiento; c) Incoación de expedientes sancionadores a las entidades y a sus órganos de administración y dirección; d) Medidas de intervención o de sustitución de administradores.

Otras actuaciones supervisoras del Banco de España sobre las actividades de las Entidades de crédito pueden clasificarse en los siguientes apartados:

a) Transparencia e información a la clientela bancaria, a través de la verificación y registro del folleto relativo a las tarifas de comisiones por los servicios bancarios, gastos repercutibles y condiciones de valoración. Esta verificación no alcanza a las operaciones sobre valores por ser competencia de la CNMV.

b) Registros oficiales e Información institucional de Entidades, donde se incluyen el Registro de Entidades, el Registro de Altos Cargos sobre administradores y directivos de las entidades supervisadas por el Banco de España, Información confidencial acerca del accionariado de las Entidades, Declaración sobre los Agentes facultados por los establecimientos de cambio de moneda extranjera para gestionar transferencias en el exterior; y el Registro Especial de Estatutos Sociales de las entidades supervisadas donde deben figurar las sucesivas modificaciones de los mismos.

c) Otros recursos propios computables autorizados a efectos de solvencia. La emisión de estos instrumentos financieros, entre los que se encuentran las financiaciones subordinadas de duración indeterminada y las participaciones preferentes emitidas en muchos casos por sociedades instrumentales filiales de las Entidades de crédito, es libre pero el Banco de España debe verificar que cumplen las condiciones previstas en la normativa sobre solvencia bancaria como requisito previo para su cómputo como recursos propios de la entidad emisora o de su grupo consolidable.

\section{C) El ejercicio de la potestad sancionadora del Banco de España}

La potestad sancionadora ejercida sobre los sujetos y mercados cuyo control e inspección corresponde al Banco de España constituye la actividad de cierre de dicha función supervisora, configurándose como un mecanismo encaminado a garantizar

4 “Memoria de la Supervisión Bancaria en España", Banco de España. Esta memoria se publica anualmente, siendo la correspondiente al año 2008 la última publicada. 
el cumplimiento de la normativa de ordenación y disciplina. Como señala la Exposición de Motivos de la LDIEC "la eficacia de las normas depende de la existencia de unas facultades coercitivas suficientes en manos de las autoridades supervisoras de las entidades financieras, cuyo desarrollo, a través de un régimen adecuado de sanciones administrativas, debe cerrar el sistema regulador".

\section{a) Tramitación de expedientes sancionadores}

En el año 2008, según la citada “Memoria de la Supervisión Bancaria en España 2008", se han acordado la incoación de 14 expedientes sancionadores. Atendiendo a la tipología de los sujetos que han sido objeto de los expedientes, se observa que tres se han incoado a sociedades de tasación homologadas y 10 a sus administradores y directivos; seis expedientes a establecimientos de cambio de moneda extranjera y gestión de transferencias en el exterior y 23 a sus altos cargos; un expediente a una persona física y otra jurídica por la adquisición de participaciones significativas en el capital de un establecimiento financiero sin haberlo comunicado previamente al Banco de España; un expediente a una sociedad y a su administrador único por el ejercicio de actividades reservadas a las entidades de crédito; uno a una entidad que realizaba la actividad de gestión de transferencias con el exterior sin la preceptiva autorización. Por último, se han tramitado dos expedientes por infracción del nivel de reservas mínimas en el marco del art.19 de los Estatutos del Sistema Europeo de Bancos Centrales, que otorga la competencia para su incoación y resolución al B. Central Europeo.

Los datos mencionados no representan especiales diferencias con los de años anteriores, ni en cuanto a su número ni al tipo de sujetos pasivos objeto de la actividad sancionadora, si bien cabe destacar por el contrario que existe reincidencia entre varios de ellos ya que algunos ya fueron sancionados anteriormente por haber incumplido normas de ordenación y disciplina, lo que sí resulta preocupante.

\section{b) Resolución de expedientes sancionadores}

Junto a los expedientes sancionadores incoados, mencionaremos los expedientes resueltos en el año 2008. En este año, los órganos competentes han resuelto los expedientes tramitados contra 9 entidades supervisadas y 42 miembros de sus órganos de administración y dirección.

En dichas resoluciones, se han impuesto 12 sanciones a entidades y 26 a administradores y directivos por la comisión de infracciones muy graves. Por la comisión de infracciones graves se han impuesto 26 sanciones a entidades y 87 a sus altos cargos, mientras que por infracciones leves se han impuesto 6 sanciones solamente a entidades ya que el ordenamiento jurídico no prevé sanciones por faltas leves a administra-

254 dores o directivos. Además, se han resuelto tres expedientes sancionadores por in- 
cumplimiento del coeficiente de reservas mínimas que, como hemos dicho, corresponde su resolución al BCE y su tramitación al Banco de España5.

\section{c) Tipos de Sanciones}

Dentro de los distintos tipos de sanciones que establece la normativa sancionadora, la mayoría de las sanciones impuestas son de naturaleza pecuniaria. Sin embar-

5 En relación con los expedientes sancionadores resueltos por el Banco de España, interesa destacar a continuación cuales son las infracciones habituales de este tipo de entidades y sujetos de los mercados financieros según se establece en la normativa sancionadora citada, atendiendo además al tipo de entidad de que se trate: 1 . Entidades de Crédito: Se ha resuelto un expediente sancionador contra un Banco y 16 cargos de administración y dirección de la entidad, en relación con la infracción grave relativa al incumplimiento de las normas sobre contabilización de operaciones y sobre formulación de balances, cuenta de pérdidas y ganancias y estados financieros de obligatoria comunicación al órgano administrativo competente.

2. Sociedades de Tasación: Se ha resuelto un expediente sancionador contra una Sociedad de tasación y sus cinco cargos de administración, en el que se ha apreciado la existencia de cuatro infracciones, una muy grave y tres graves. La infracción muy grave consiste en el incumplimiento del requisito consistente en disponer de medios organizativos y de control interno necesarios para desarrollar la actividad de tasación. Las infracciones graves consisten en la emisión de certificados e informes de tasación en cuyo contenido existe discordancia con los datos y pruebas obtenidos en la valoración efectuada; en la falta de remisión de datos al Banco de España; y en el incumplimiento de la exigencia aplicable a este tipo de entidades de tener suscrito una póliza de responsabilidad civil con ciertas condiciones. Esta infracción, que en principio es leve, pasa a ser grave por reincidencia en la misma por la entidad sancionada en los dos años precedentes.

3. Establecimientos de cambio de moneda y gestión de transferencias en el exterior: Estos expedientes sancionadores son los más numerosos en los últimos años. En el año 2008, se han dirigido contra siete entidades y 21 administradores y directivos. Las infracciones muy graves han consistido en llevar la contabilidad con irregularidades esenciales que impidan conocer la situación patrimonial y financiera del establecimiento; en la omisión de información que debe remitirse al Banco de España por cuanto con ello se dificulta la apreciación de la situación patrimonial y financiera del establecimiento; y en incurrir de nuevo las mismas entidades en faltas graves por las que ya habían sido sancionadas en los últimos cinco años precedentes consistentes en el incumplimiento de la exigencia de exclusividad en la utilización de las cuentas bancarias a través de las que se canalizan los fondos transferidos, de la normativa sobre agentes, de las normas sobre transparencia de las operaciones, y de la normativa reguladora del registro de operaciones.

En cuanto a las infracciones graves, se han sancionado a estos establecimientos por el incumplimiento de la normativa reguladora del nivel mínimo de capitalización de los establecimientos de cambio; de la obligada cobertura de la responsabilidad civil derivada de la gestión de transferencias; de las obligaciones sobre registro de las operaciones y gestión de transferencias; de las previsiones normativas sobre transparencia y protección de la clientela; del deber de exclusividad de las cuentas de canalización de transferencias con el exterior; y por la existencia de inexactitudes y omisiones en la información remitida al Banco de España. Finalmente, en relación con las infracciones leves, éstas afectan a incumplimientos aislados de la normativa sobre agentes; a incumplimientos de la normativa sobre transparencia y protección de la clientela; a la realización aislada de actividades ajenas al objeto social exclusivo; y a la falta de remisión en plazo al Banco de España de documentación.

4. Realización de actividades reservadas a las entidades supervisadas: Como ya hemos comentado, la actividad sancionadora del Banco de España se dirige igualmente a aquellas personas físicas o jurídicas que, sin estar debidamente autorizadas ni figurar en los correspondientes registros, realizan actividades reservadas a las entidades de crédito. En el año 2008, se ha dictado resolución sobre un expediente dirigido contra una sociedad y contra su administrador único por la realización de actividades de captación de fondos reembolsables al público en forma de préstamo. Estas actividades afectan especialmente a la confianza del público en el sistema financiero, cuyo funcionamiento se ve alterado por la actividad intrusora del infractor y afecta gravemente a los intereses y derechos económicos de los titulares de los recursos financieros aportados que asumen el riesgo de pérdida en caso de insolvencia de los infractores perceptores de los fondos. 
go, la finalidad de la potestad disciplinaria en este ámbito financiero no es tanto el castigo de conductas, que va implícito en el ejercicio de cualquier procedimiento sancionador, sino la protección del sistema, evitando con ello futuros incumplimientos y el mantenimiento de la confianza de los ciudadanos y clientes de las entidades. Por ello, en algunos casos, el Banco de España ha optado por la imposición de otras sanciones como la amonestación pública y privada, así como la inhabilitación de altos cargos. En el año 2008, además de lo anteriormente dicho, en tres ocasiones se ha considerado necesario revocar la autorización concedida a otros tantos establecimientos de cambio de moneda extranjera al estimarse que las infracciones cometidas, por su gravedad o por su persistencia, los hacía no idóneos para permanecer en el sistema.

Como conclusión de lo anteriormente expuesto, debe ponerse de manifiesto que la actividad sancionadora del Banco de España en los últimos años, se ha mantenido dentro de los mismos parámetros y tendencias tanto en lo que respecta al número de expedientes tramitados y resueltos, como a la naturaleza de los sujetos expedientados y los tipos de sanciones impuestas. En este último aspecto, merece destacarse que en todos los expedientes sancionadores donde se ha apreciado la existencia de infracciones muy graves o graves, se ha sancionado además de a las entidades afectadas, también a sus administradores y directivos al haberse probado su responsabilidad en la comisión de esas infracciones.

\section{EL MARCO LEGAL REGULADOR DE LOS MERCADOS FINANCIEROS}

El marco legal que regula el sistema crediticio y financiero ha sido objeto de numerosas críticas por parte de la doctrina. Como señala Martín-Retortillo, S. "es ya un tópico, por otra parte justificado por demás, la valoración eminentemente crítica que recibe el ordenamiento bancario; o más en general si se quiere, todo el conjunto normativo que regula el sistema crediticio y financiero. Fraccionamiento; falta de rigor y de coherencia; oscuridad; dificultad casi habitual de encontrar la norma aplicable al caso concreto; también, y con frecuencia, soluciones contradictorias" ${ }^{\text {. }}$

Ciertamente, la regulación normativa de los mercados financieros, adolece de todos esos defectos pero también es cierto que muchos otros ámbitos de nuestro ordenamiento adolecen de los mismos defectos sin la justificación técnica de complejidad que sí tiene el ámbito financiero. El marco legal de los mercados financieros ha ido mejorando técnicamente en la última década, y muy especialmente las modificaciones parciales de nuestras dos grandes Leyes en este sector, como son la Ley 24/1988, de 28 de julio, de Mercado de Valores y la Ley 26/1988, de 29 de julio, sobre Disciplina e Intervención de las Entidades de Crédito. A todo ello, sin duda, ha contribuido en gran medida la necesaria trasposición de la normativa comunitaria que ha

6 Martín-Retortillo Baquer, S. "Reflexiones sobre la Ley de Disciplina e Intervención Bancaria”, 256 R.A.P., n. ${ }^{\circ} 118,1989$, págs. 7-34. 
ido, sin pausa, elaborando y aprobando por parte del Parlamento Europeo y del Consejo de la Unión Europea una transformación del sector financiero a través de normas de hondo calado tanto en la vertiente interna de la actividad financiera, esto es en la organización, financiación y solvencia de las entidades, como en el aspecto externo de la misma es decir en las relaciones entre las entidades y su clientela.

\section{Normativa relativa a la ordenación de la actividad interna y del capital}

En relación con la ordenación de la actividad interna y del capital, destacan recientemente tres Leyes, la Ley 36/2007, de 16 de noviembre, la Ley 41/2007, de 7 de diciembre, y la Ley 5/2009, de 29 de junio.

Como desarrollo complementario de la Ley 36/2007, se ha aprobado el Real Decreto $216 / 2008$, de 15 de febrero (BOE 16 de febrero), de recursos propios de las entidades financieras, y que igualmente desarrolla reglamentariamente la Ley 47/2007, de 19 de noviembre, que modifica parcialmente la LMV 24/1988, de 28 de julio, en lo relativo a los aspectos sobre solvencia de las empresas de servicios de inversión. El Real Decreto 216/2008 da continuidad así a la trasposición de las Directivas 2006/48/ CE relativa al acceso a la actividad de las entidades de crédito y a su ejercicio, y 2006/49/CE sobre adecuación del capital de las empresas de servicios de inversión y las entidades de crédito. El nuevo régimen de solvencia, y que ha sido traspuesto mediante las normas legales citadas y el Real Decreto 216/2008, ha sido a su vez culminado mediante las correspondientes especificaciones técnicas establecidas en las Circulares del Banco de España 3/2008 de 22 de mayo, y 5/2008 de 31 de octubre relativas respectivamente a los recursos propios mínimos de las Entidades de crédito, y de las Sociedades de garantía recíproca.

Otras normas reglamentarias relativas a la actividad de las entidades financieras son el Real Decreto 217/2008, de 15 de febrero, relativo a las empresas de servicios de inversión, entre las que las entidades de crédito ocupan un lugar predominante, y el Real Decreto 322/2008, de 29 de febrero, sobre el régimen jurídico de las entidades de dinero electrónico.

A) La Ley 36/2007, de 16 de noviembre (BOE del día 17), modifica la Ley 13/1985, de 25 de mayo, de coeficientes de inversión, recursos propios y obligaciones de información de los intermediarios financieros y otras normas del sistema financiero. Esta Ley traspone parcialmente la Directiva 2006/48/CE del Parlamento Europeo y del Consejo de la UE, e incorpora al régimen jurídico nacional el denominado Acuerdo de Basilea II con los objetivos, entre otros, de asegurar un adecuado nivel de solvencia y mejora la igualdad competitiva entre las Entidades de Crédito haciendo el capital regulatorio exigido más sensible a los riesgos reales e incentivando una mejor gestión de los mismos?.

7 La Directiva citada consagra el principio de gastos compartidos en virtud del cual el ordenante y el beneficiario pagan los correspondientes a sus propios proveedores de servicios de pago (gastos has- 
La Ley introduce nuevas obligaciones de información y divulgación al público. Así, establece el deber de publicar, al menos una vez al año, un documento denominado "información con relevancia prudencial", sobre sus actividades y situación financiera, con el fin que el mercado y otras partes interesadas puedan evaluar los riesgos de las entidades, sus estrategias, sus mecanismos de control y su solvencia. Aun cuando los contenidos mínimos de este documento lo fijará el Banco de España, cada entidad deberá fijar una política formal de divulgación de información ${ }^{8}$.

Estas obligaciones han tenido reflejo, asimismo, en la LDIEC, en la que se han introducido los correspondientes tipos infractores, además de la obligación de contar con una estructura organizativa adecuada, con líneas de responsabilidad bien definidas, transparentes y coherentes, que, en el caso de entidades de crédito que presten servicios de inversión, deberá respetar los requisitos organizativos establecidos en la Ley $24 / 1988$, de 28 de julio, del Mercado de Valores 9 .

B) En segundo lugar, en relación con esta misma actividad interna y del capital, se ha aprobado la Ley 41/2007, de 7 de diciembre (BOE del día 8 de diciembre), por la que se modifica la Ley $2 / 1981$, de 25 de marzo, de regulación del mercado hipotecario, y otras normas del sistema hipotecario y financiero, de regulación de las hipotecas inversas y el seguro de dependencia y por la que se establece determinada norma tributaria.

Desde el punto de vista que aquí nos ocupa, dos son las modificaciones fundamentales de esta Ley: de un lado, la introducción de mejoras técnicas en los instrumentos de financiación de la actividad hipotecaria, y, de otro, la modificación del régimen supervisor de las entidades de tasación. Junto a estos cambios, la Ley introduce otros que van desde la regulación de las relaciones de las entidades con su cliente -transparencia en la contratación de préstamos hipotecarios, régimen de compensación por amortización anticipada, hipoteca inversa y seguros de dependencia- a la introducción de mejoras técnicas en el marco jurídico hipotecario.

ta la frontera). En lo que concierne a los requerimientos mínimos de recursos propios de los grupos consolidables de entidades de crédito y de las no integradas en un grupo consolidable, la Ley 36/2007 explicita ahora un conjunto de riesgos que, en todo caso, y sin perjuicio de otros, deben ser objeto de cobertura. Estos riesgos son: para todas las actividades, el de tipo de cambio, el relativo a las materias primas y el operacional; para todas las actividades excepto las de la cartera de negociación, el riesgo de crédito y el de dilución; y, para la cartera de negociación, el de posición, el de liquidación y el de contraparte.

8 Igualmente, se exige a las entidades de crédito el establecimiento de estrategias y procedimientos sólidos, eficaces y exhaustivos, que permitan evaluar, mantener y distribuir adecuadamente un nivel de capital interno adecuado al nivel de riesgos. En el caso de los grupos consolidables estos mecanismos deberán ser coherentes, y estar bien integrados.

9 Adicionalmente, se otorgan al Banco de España nuevas facultades ejecutivas para el ejercicio de su labor disciplinaria en su condición de autoridad responsable de la supervisión de las entidades de crédito y sus grupos consolidables. Así, en relación con el cumplimiento por parte de estas entidades de las obligaciones de solvencia, el Banco de España podrá obligarles a mantener recursos propios adicionales a 258 los exigidos con carácter mínimo; exigir la aplicación de políticas específicas de reducción de riesgos, y restringir o limitar los negocios, las operaciones o la red de las entidades. 
En relación con lo que aquí más nos interesa ahora, que son las modificaciones del régimen supervisor de las entidades de tasación, la Ley aborda tres ámbitos de actuación bajo el principio básico de mantener y reforzar la profesionalidad e independencia de las mismas. En primer lugar, establece que, en determinados casos, dichas entidades deberán disponer de mecanismos adecuados para favorecer su independencia y evitar conflictos de intereses. Concretamente, en los supuestos típicos en que presten sus servicios a entidades de crédito de su mismo grupo, o cuando sus ingresos totales deriven al menos, en el periodo temporal que se establezca, en un $25 \%$ de su relación con una entidad de crédito o conjunto de entidades de un mismo grupo que tenga en circulación títulos hipotecarios.

Por otra parte, la Ley modifica el régimen sancionador de las entidades de tasación, tipificándose nuevos supuestos de infracción derivados del nuevo régimen de obligaciones contenido en la Ley, al tiempo que se revisan y actualizan los ya existentes. $Y$, en tercer lugar, con la finalidad de asegurar una adecuada gestión de las entidades de tasación, se establece un régimen de participaciones significativas similar al previsto para las entidades de crédito ${ }^{10}$.

La reciente Ley 5/2009, de 29 de junio (BOE del 30 de junio), supone igualmente un importante avance y modificación en la regulación del régimen de participaciones significativas en empresas de servicios, en entidades de crédito y en entidades aseguradoras. Esta nueva Ley modifica hasta tres normas con rango de Ley, la Ley 24/1988, la Ley $26 / 1988$, y el T.R. de la Ley de ordenación y supervisión de los seguros privados, aprobado por el R.D. Legislativo 6/2004, de 29 de octubre, y supone la trasposición de la nueva Directiva 2007/44/CE del Parlamento Europeo y del Consejo, de 5 de septiembre de 2007 que modifica las Directivas 92/49, 2002/83, 2004/39, 2005/68 y 2006/48 en lo relativo a las normas procedimentales y los criterios de evaluación aplicables en relación con la evaluación cautelar de las adquisiciones y de los incrementos de participaciones en el sector financiero"11.

La Ley 5/2009, de 29 de junio, tiene como finalidad, de conformidad con la Directiva $2007 / 44 / C E$, incrementar la claridad y eficacia del régimen de participaciones significativas mejorando la seguridad jurídica y claridad necesarias de todo el proceso de evaluación para los tres sectores financieros implicados: entidades de crédito, em-

10 A los efectos de esta Ley, se entenderá por participación significativa en una sociedad de tasación aquella que alcance, de forma directa o indirecta, al menos el 15\% del capital o de los derechos de voto de la sociedad, o aquella que, sin llegar al porcentaje señalado, permita ejercer una influencia notable en la sociedad. La adquisición directa o indirecta de una participación significativa en una sociedad de tasación llevará aparejada la obligación de informar previamente al Banco de España, quien dispondrá de un plazo de tres meses para, en su caso, oponerse a la adquisición que se quiere llevar a efecto.

11 Esta nueva norma comunitaria modifica las cinco directivas que regulan, respectivamente, el seguro de vida y el seguro distinto del de vida, los mercados de instrumentos financieros, el reaseguro y el acceso a la actividad de las entidades de crédito con el objeto de reformar, de forma homogénea, el régimen de participaciones significativas. La trasposición que lleva a cabo la Ley 5/2009 es, no obstante, parcial en cuanto que queda sujeta al desarrollo reglamentario posterior de sus extremos más técnicos. 
presas de servicios de inversión y entidades aseguradoras y reaseguradoras. La Ley consta de tres artículos que se refieren respectivamente a las modificaciones necesarias en las tres Leyes citadas, con los ajustes propios necesarios para cada articulado con el fin de conseguir el mismo régimen de participaciones significativas en las tres normas legales.

En primer lugar, y en cuanto afecta al régimen de obligaciones de los sujetos financieros y el correspondiente régimen sancionador, esta Ley modifica la LMV en relación con el artículo 69 y adiciona un nuevo apartado 2 al artículo 60 quater y una nueva letra j) ter en el artículo 100 como infracción grave.

En segundo lugar, modifica la LDIEC en relación con los artículos 5 letra w, 43.5, $56,57,58,58$ bis, 59 y 60 que afectan principalmente al Título VI de la Ley que regula el Régimen de las participaciones significativas. Y, en tercer lugar, modifica el T.R. de la Ley de ordenación y supervisión de los seguros privados aprobado por el R.D. Legislativo 6/2004, de 29 de octubre, en relación con los artículos 5.2 e), 22, 22 bis, 22 ter, 22 quater, 40.3 f) y g), 58 bis g) y 77.4 párrafo $2 .^{\circ}$

Al margen de la incorporación de la normativa comunitaria al derecho interno en relación con estas tres Leyes, la Ley 5/2009 modifica igualmente la Ley 26/2006, de 17 de julio, de mediación de seguros y reaseguros privados, en su artículo 28, estableciendo un régimen de mera comunicación, que sustituye al hasta ahora existente de autorización previa, a la D.G. de Seguros y Fondos de Pensiones de la proyectada transmisión de acciones o participaciones que pudiera dar lugar a un régimen de participaciones significativas con el establecimiento del plazo de tres meses para oponerse a la misma por parte de la citada D.G. de Seguros.

Igualmente, por último, establece una modificación en el artículo 45 de la Ley 35/2003, de 4 de noviembre, de Instituciones de Inversión Colectiva en relación con el régimen de participaciones significativas que afecta tanto al régimen sancionador recogido en el Título VI de la Ley 35/2003, como al régimen de intervención de la empresa previsto en el artículo 72 y a la sustitución de sus administradores si fuera preciso.

\section{Normativa relativa a la ordenación de la actividad externa de las entidades y su clientela}

En relación con las modificaciones legales entre las entidades y su clientela, destacan la Ley 22/2007, de 11 de julio, sobre comercialización a distancia de servicios financieros destinados a consumidores, la Ley 41/2007, de 7 de diciembre, ya referida de regulación del mercado hipotecario, y la Ley 47/2007, de 19 de diciembre, por la que se modifica la Ley $24 / 1988$, de 28 de julio, del mercado de valores.

Pese a la intensa reflexión normativa desarrollada a nivel internacional en gene260 ral y comunitario en particular, en el ámbito que nos ocupa tan sólo se ha aprobado 
en el año 2008 en la UE una medida regulatoria consistente en la Directiva 2008/48/ CE de 23 de abril de 2008 relativa a los contratos de crédito al consumo y por la que se deroga la Directiva 87/102/CEE del Consejo. Esta Directiva tiene por objeto la reducción de las diferencias existentes en el ámbito del crédito al consumo en las legislaciones de los Estado miembros a fin de conseguir el establecimiento de un verdadero mercado interior del crédito al consumo. Para ello, otorga una gran importancia a los derechos de los consumidores, entre los que destaca el derecho de información que tanto el prestamista como, en su caso, el intermediario deben suministrar a los consumidores con carácter previo a la celebración del contrato, y que se sintetiza en la denominada "Información normalizada europea sobre el crédito al consumo".

Como respuesta a la grave crisis financiera internacional, en el último trimestre del año 2008, se aprobaron diversas medidas urgentes con el doble objetivo de aumentar la estabilidad del sistema financiero a través del incremento de la confianza de los inversores y depositantes, y mejorar la creciente dificultad de las entidades de crédito para captar recursos en los mercados de capitales con motivo de las incertidumbres sobre los riesgos de crédito.

Así, se han aprobado el Real Decreto-Ley 6/2008, de 10 de octubre, por el que se crea el Fondo para la adquisición de activos financieros (por importe de 30.000 millones de euros ampliables hasta 50.000, con cargo a los Presupuestos generales del Estado); el Real Decreto Ley $7 / 2008$, de 13 de octubre, de medidas urgentes en materia económico-financiera en relación con el Plan de Acción concertada de los Países de la Zona Euro; el Real Decreto 1642/2008, de 10 de octubre, por el que se aumentan los importes garantizados de los depósitos hasta 100.000 euros; y el Real Decreto 1975/2008, de 28 de noviembre, sobre las medidas urgentes a adoptar en materia económica, fiscal, de empleo y de acceso a la vivienda.

A) La Ley 22/2007, de 11 de julio, sobre comercialización a distancia de servicios financieros destinados a consumidores (BOE del día 12 de julio), establece el régimen específico que habrá de aplicarse a los contratos con consumidores de servicios financieros celebrados a distancia(sin presencia física simultánea), directamente o a través de intermediario, por entidades financieras o sucursales extranjeras establecidas en España, o en otros Estados miembros de la Unión Europea o del Espacio económico europeo (EEE); en este último caso, cuando el destinatario resida en España y resulte afectada alguna de estas materias: publicidad de las instituciones de inversión colectiva (IIC), seguro directo, operaciones con consumidores, régimen de elección por las partes de la legislación aplicable al contrato, licitud de las comunicaciones y bienes inmuebles sitos en España.

El objeto principal de la Ley es la protección de los consumidores. Para ello, establece una serie de mecanismos tales como nulidad de la renuncia de los consumidores a los derechos que en ella se les reconocen, el establecimiento de un riguroso y detallado régimen de información con carácter previo a la celebración del contrato o a la asunción de obligaciones, la regulación del derecho de desistimiento, con absolu- 
ta libertad y sin motivos, en un plazo de14 días, y 30 días para los contratos relacionados con seguros de vida, todo ello a excepción de aquellos servicios cuyas condiciones contractuales exijan una seguridad jurídica especial.

La Ley establece un régimen sancionador que, en el caso de sociedades supervisadas, remite al previsto en su normativa específica y, en el de otras entidades, al establecido en la normativa de consumo. De forma subsidiaria, se aplicará el régimen establecido en la Ley 34/2002 de servicios de la sociedad de información y del comercio electrónico.

B) La Ley 41/2007, de 7 de diciembre, por la que se modifica la Ley 2/1981, de 25 de marzo, de regulación del mercado hipotecario, y que ya hemos analizado en el apartado anterior en relación con sus disposiciones de tipo organizativo y financiero.

En cuanto a la incidencia externa de esta Ley en sus aspectos favorecedores de los ciudadanos, extiende a todo tipo de hipotecas sobre viviendas las obligaciones de información en virtud de la aplicación de la transparencia en la contratación de préstamos hipotecarios. Igualmente, la Ley favorece la cancelación anticipada de su deuda mediante la sustitución de la comisión de amortización anticipada por una compensación por desistimiento y amplía los beneficios fiscales de las subrogaciones y novaciones hipotecarias así como la reducción de los aranceles de notarios y registradores ${ }^{12}$.

C) La Ley $47 / 2007$, de 19 de diciembre, por la que se modifica la Ley $24 / 1988$, del mercado de valores, es una Ley de amplio contenido que traspone las Directivas 2004/39/CE y 2006/49/CE, ambas del Parlamento Europeo y del Consejo de la Unión Europea, y que regula múltiples aspectos relacionados con los cuatro grupos siguientes de asuntos: 1.La solvencia y supervisión de las empresas de servicios de inversión (ESI); 2.Los requisitos de organización de las entidades que prestan servicios de inversión; 3. Las condiciones en las que han de prestarse tales servicios; 4. Los requisitos exigibles a los mercados regulados, a los sistemas multilaterales de negociación y a la internalización sistemática, figuras estas últimas de nueva creación.

La Ley $47 / 2007$ ha introducido importantes cambios en el mercado de valores tales como la delimitación de los instrumentos financieros, la nueva regulación de los mercados secundarios oficiales y la introducción de nuevas formas alternativas de negociación, la creación de nuevas empresas de servicios de inversión y de nuevos servicios de inversión, el establecimiento de nuevas normas de conducta y la actualización del régimen de solvencia y supervisión.

12 Esta Ley regula nuevos productos financieros como la hipoteca inversa que consiste en un préstamo o crédito hipotecario formalizado mediante hipoteca sobre un bien inmueble que constituye la vivienda habitual del solicitante con el cumplimiento de diversos requisitos como son: que el solicitante y los beneficiarios tengan al menos 65 años, que el deudor hipotecario disponga del importe mediante disposiciones periódicas o de una sola vez, que la deuda sólo sea exigible por el acreedor cuando fallezca el pres- 
Las nuevas obligaciones introducidas por la Ley 47/2007 tienen una repercusión directa nuevamente en el régimen sancionador, al modificar significativamente la LMV tanto en su Título VIII, capítulo II sobre Infracciones y sanciones, artículos 99 a 100, en su Título $V$ "Empresas de servicios de inversión", que establece las condiciones de ejercicio de estas empresas, y en su Título VII relativo a "normas de conducta" aplicables a quienes presten servicios de inversión. El Título VII se reestructura con la creación de dos capítulos, el primero recoge las obligaciones con los clientes y el segundo relativo a evitar el abuso de mercado regulando la información privilegiada, la difusión de información relevante, la libre formación de precios de los valores, y la obligación de comunicar operaciones sospechosas. Tienen la consideración de empresas de servicios de inversión, artículo 64 de la LMV, las siguientes: a) las sociedades de valores, b) las agencias de valores, c) las sociedades gestoras de carteras, y d) las empresas de asesoramiento financiero.

Los artículos 99 y 100 de la LMV recogen las infracciones muy graves y graves respectivamente, y tipifican el incumplimiento de las obligaciones de las empresas que prestan servicios de inversión y que se establecen principalmente en los artículos 70 a 70 quater, artículos 79 a 79 sexies, y artículos 81 a 83 quater. Los artículos 70 a 70 quater establecen sus requisitos financieros y organizativos internos, debiendo tener una estructura organizativa adecuada a los servicios que presten, una unidad de cumplimiento normativo, un sistema de información que asegure el conocimiento de obligaciones, riesgos y responsabilidades, y medidas organizativas adecuadas para controlar las operaciones realizadas a título personal por sus directivos y empleados, y para evitar que potenciales conflictos de interés perjudiquen a sus clientes.

Los artículos 79 a 79 sexies se incluyen en el Título VII relativo a Normas de conducta como ya hemos comentado. Unos de los principales objetivos de la reforma es lograr una protección eficaz de los clientes de los servicios de inversión. El artículo 79 establece la obligación de diligencia y transparencia con sus clientes cuidando de los intereses de sus clientes como si fueran propios. Las obligaciones de información y registro se recogen en el artículo 79 bis a 79 quinquies, mientras que el artículo 79 sexies regula las obligaciones relativas a la gestión y ejecución de órdenes ${ }^{13}$.

13 La Ley distingue tres categorías de inversores, a las que otorga distinto grado de protección: clientes minoristas, clientes profesionales (los que cuentan con experiencia, conocimientos y cualificación necesaria para tomar sus propias decisiones de inversión) y contrapartes elegibles (clientes profesionales regulados y organismos públicos). El mayor grado de protección se otorga a los primeros.

Destacaremos, entre todas, las obligaciones de estas entidades -que son tan importantes para los ciudadanos, los cuales por otra parte son clientes obligados de las mismas en la compraventa de valores-, la consistente en que cuando se preste el servicio de asesoramiento o gestión de carteras, la entidad debe tener en cuenta tanto los conocimientos y experiencia del cliente minorista como su situación financiera y sus objetivos de inversión, mientras que para el resto de los servicios, sólo deberá solicitar al cliente, incluidos los potenciales, información sobre sus conocimientos y experiencia en relación con el tipo concreto de producto o servicio ofrecido o solicitado. No obstante, cundo el servicio prestado sea la ejecución o recepción y transmisión de órdenes a iniciativa del cliente, bastará cumplir determinadas condiciones organizativas y de información. 
Por último, las obligaciones que se agrupan bajo el capítulo II "Abuso de mercado" en los artículos 80 a 83 quater son y han sido de gran interés en la Jurisprudencia de los Tribunales, regulando el uso de información privilegiada, la obligación de difundir y hacer pública la información relevante, las prácticas que falseen la libre formación de los precios, así como la obligación de todas las entidades que operan con instrumentos financieros de avisar a la CNMV de las operaciones sospechosas de haber utilizado información privilegiada o de haber falseado la libre formación de los precios.

\section{EL CONTENIDO MATERIAL DEL RÉGIMEN SANCIONADOR DE LAS ENTIDADES DE CRÉDITO REGULADO EN LA LEY 26/1988 DE DISCIPLINA E INTERVENCIÓN}

Veremos a continuación el contenido material de la regulación que se establece en la LDIEC, y cuya competencia tanto en el ámbito sancionador como en el de aprobación de medidas de intervención y sustitución corresponde principalmente, como hemos visto, al Banco de España.

La Ley establece en su Título I (artículos 1 a 27) el Régimen sancionador y en el Título III (artículos 31 a 38) las Medidas de intervención y de sustitución, dedicando el Titulo IV (artículos 39 a 48) a establecer Disposiciones Complementarias relativas principalmente al Régimen sancionador. Estos tres Títulos constituyen más del $70 \%$ del articulado de la misma, regulando en los restantes Títulos, el ejercicio de actividades y uso de denominaciones reservadas a las entidades de crédito (Título II, artículos 28 a 30), el ejercicio de la actividad crediticia en los Estados miembros de la Comunidad Europea (Título V, artículo 49 a 55), y por último el régimen de las participaciones significativas (Título VI, artículos 56 a 61).

El contenido material de la LDIEC dista mucho de la redacción inicial que fue aprobada con fecha 29 de julio de 1988, habiendo sido modificada parcialmente en numerosas e importantes Leyes sobre el sistema financiero en una mejora continua de la misma que ha afectado especialmente a la tipificación de las infracciones recogidas en su régimen sancionador ${ }^{14}$.

14 Así, destacamos la Ley 3/1994, de 14 de abril, de adaptación a la segunda Directiva de Coordinación Bancaria; Ley 44/2002, de 22 de noviembre, de medidas de reforma del sistema financiero; Ley 5/2005, de 22 de abril, de supervisión de los conglomerados financieros y modificación de otras leyes del sector financiero; Ley 36/2007, de 16 de noviembre, que modifica la Ley 13/1985 de coeficientes de inversión, recursos propios y obligaciones de información de los intermediarios financieros y otras normas del sistema financiero; el Real Decreto-Ley 9/2009, de 26 de junio; y la Ley 5/2009, de 29 de junio, por la que se modifican las Leyes 24/1988 del mercado de valores, el Texto refundido de la Ley de ordenación y supervisión de los 264 seguros privados, aprobado mediante Real Decreto Legislativo 6/2004, y la presente Ley 26/1988 de Disci- 


\section{Características generales}

La presente LDIEC establece una normativa sancionadora común para el conjunto de las entidades de crédito que sustituye a la denominación anterior de "establecimientos de crédito", y que se extiende además a otro tipo de instituciones financieras que desarrollan esencialmente la actividad que define a una entidad de crédito.

Tienen la consideración de Entidades de Crédito a los efectos de lo dispuesto en esta Ley, según establece el artículo 1.2, las entidades enumeradas en el apartado segundo del artículo 1. ${ }^{\circ}$ del Real Decreto Legislativo 1298/1986, de 28 de junio, siendo de aplicación igualmente a las sucursales abiertas en España por entidades de crédito extranjeras. La Ley 44/2002, de 22 de noviembre, ha dado nueva redacción al artículo 1 del Real Decreto Legislativo 1298/1986 y lo incorpora, además, como artículo 39.3 de la LDIEC, disponiendo que se entiende por Entidad de crédito "toda Empresa que tenga como actividad típica y habitual recibir fondos del público en forma de depósito, préstamo, cesión temporal de activos financieros u otras análogas que lleven aparejada la obligación de su restitución, aplicándose por cuenta propia a la concesión de créditos u operaciones de análoga naturaleza"n.

La Ley señala como sujetos pasivos de la potestad sancionadora además de las entidades de crédito también a quienes ostenten cargos de administración o dirección de las mismas, que son delimitados y definidos en su artículo 1.4. Así, constituyen cargos de administración o dirección en las entidades de crédito, sus administradores o miembros de sus órganos colegiados de administración, sus directores generales o asimilados, entendiéndose por tales aquellas personas que desarrollen en la entidad funciones de alta dirección bajo la dependencia directa de su órgano de administración o de comisiones ejecutivas o consejeros delegados del mismo, así como las personas que dirijan las sucursales de entidades de crédito extranjeras en España ${ }^{16}$.

El artículo 15.1 de la Ley establece que "Quien ejerza en la entidad de crédito cargos de administración o dirección será responsable de las infracciones muy graves o graves cuando estas sean imputables a su conducta dolosa o negligente".

15 Se conceptúan en particular Entidades de crédito: a)El Instituto de Crédito Oficial y las Entidades Oficiales de crédito;b)Los Bancos privados;c)Las Cajas de Ahorros, la Confederación Española de Cajas de Ahorros y la Caja Postal de Ahorros; d)Las Cooperativas de Crédito; e)Las Sociedades de Crédito Hipotecario; f)Las Entidades de Financiación; g)Las Sociedades de Arrendamiento Financiero; h)Las Sociedades Mediadoras del Mercado de Dinero.

16 La Circular 13/1988, de 27 de octubre, del Banco de España relativa a Altos cargos de Entidades de Crédito (BOE de 15 de noviembre) establece la obligación de dichas entidades de informar al mismo de las personas que ostentan dichos cargos cumplimentando el formulario anejo a dicha Circular, adaptado posteriormente a lo dispuesto en la Circular 11/1996 de 29 de noviembre, con el fin de proceder a su inscripción en el Registro de Altos Cargos. En el caso de los establecimientos financieros de crédito, a la solicitud de inscripción debe acompañarse el documento que acredite la aceptación del cargo. Igualmente, debe remitirse al Banco de España cualquier variación posterior que se produzca de los cargos o de los datos notificados en el plazo de quince días desde la misma. 
No obstante lo señalado en el párrafo anterior, el apartado dos del artículo 15 establece que los administradores o miembros de los órganos colegiados de administración de las entidades de crédito serán considerados responsables de las infracciones muy graves y graves cometidas por dichas entidades, salvo en los siguientes casos: a) cuando no hubiesen asistido por causa justificada a las reuniones correspondientes o hubiesen votado en contra o salvado su voto en relación con las decisiones o acuerdos que dén lugar a las infracciones y b) cuando dichas infracciones sean exclusivamente imputables a comisiones ejecutivas, consejeros-delegados, directores generales u órganos asimilados, u otras personas con funciones en la entidad.

Así, la Ley lo que persigue es sancionar tanto a la persona jurídica que indebidamente se ha beneficiado con la comisión de la infracción, como a la persona física que incumpliendo sus deberes de actuación la haya adoptado. Responsabilidad directa de la persona jurídica, tal y como lleva reconociendo explícitamente el Tribunal Constitucional desde su sentencia n. ${ }^{\circ} 246 / 1991$, de 19 de diciembre, junto con el reconocimiento de su capacidad infractora en el ámbito del Derecho administrativo sancionador, con una modulación en la aplicación del elemento subjetivo de la culpa en relación con las personas físicas. El Tribunal Constitucional alude a ello en los siguientes términos: "Esta construcción distinta de la imputabilidad de la autoría de la infracción a persona jurídica nace de la propia naturaleza de la ficción jurídica a la que responden estos sujetos. Falta en ellos el elemento volitivo en sentido estricto, pero no la capacidad de infringir las normas a las que están sometidos".

La responsabilidad de los actos de administración o dirección que establece el artículo 15 de la Ley no es una responsabilidad objetiva o sin culpa por el mero hecho de la ostentación de un cargo o la pertenencia al Consejo de Administración sino que "la infracción cometida por la entidad debe ser consecuencia de una conducta culpable que sea imputable a la acción u omisión deliberada o no diligente del titular del cargo". (Sentencia del Tribunal Supremo, de 18 de octubre 2006, TOL 1009686, que cita en este párrafo la Sentencia de la misma Sala de lo contencioso-administrativo de fecha 23 de noviembre 1998).

Ahora bien, y de conformidad con lo que hemos visto que establece el apartado 2 del artículo 15, la propia Sentencia de 18 de octubre de 2006 recuerda, con cita de otra Sentencia de la misma Sala de 17 diciembre 1997 (TOL 196.881), que estos altos cargos poseen unos especiales requisitos de experiencia y conocimientos profesionales a los que les es exigible un deber de vigilancia, control e inspección sobre los medios personales, materiales y técnicos de la entidad que deben ejercer permanentemente, estableciéndose una presunción de responsabilidad por las infracciones cometidas por sus entidades salvo prueba en contrario, que corresponde a los mismos demostrar. La misma argumentación se contiene en la Sentencia de la Audiencia Nacional de 9 de julio de 1998 (TOL 137.209), en la que se analiza con detalle la responsabilidad de los Consejeros de las entidades, al hilo del artículo 105 de la Ley $26624 / 1988$ del Mercado de Valores, en relación con la doctrina constitucional sobre los 
principio de culpabilidad y responsabilidad, y cita, con aplicación plena al caso, la Sentencia del Tribunal Constitucional 154/1994 que analiza en el ámbito del derecho administrativo sancionador un supuesto y fija el Alto Tribunal la siguiente Doctrina por la cual:

"Tras dejar sentado que los desplazamientos legales de responsabilidad deben fundamentarse en la concurrencia de una circunstancia de carácter subjetivo para ser constitucionalmente aceptables, mantiene que de la simple titularidad de un bien o derecho, pueden derivarse responsabilidades si no se actúa diligentemente en sus facultades de control"'17.

Como ha expresado la misma Sala del Tribunal Supremo en sus Sentencias de 5 julio 2001, 3 marzo 2003 y 27 marzo 2003, "la singular cualificación de las personas físicas que administran o dirigen las entidades de que se trata lleva a presumir que su preparación les permite detectar las consecuencias probables de las prácticas que tales entidades desarrollen, haciéndolas responsables, tanto si aceptan la producción de tales consecuencias como si no adoptan las previsiones necesarias para evitarlas, en el caso de que tales prácticas sean objetivamente idóneas para producirlas"(Sentencia de 3 de marzo de 2003, relativa al caso Ibercorp Bolsa, TOL 265.240).

Baste a este respecto recordar que el artículo 127.1 del Real Decreto Legislativo 1564/1989, de 2 de diciembre, que aprueba el T.R. de la Ley de Sociedades Anónimas, exige a los consejeros de estas sociedades desempeñar su cargo "con la diligencia de un ordenado empresario y un representante legal”, diligencia que en relación con las entidades bancarias se acrecienta al recaer sus nombramientos en personas de reconocido prestigio profesional con conocimientos y experiencia para desempeñar sus funciones. De esta forma no se trata sólo que ejerzan una vigilancia sobre la actuación de otros cargos sino de llevar a cabo por sí mismos la administración de la sociedad (artículo 9 L. S. A.) ${ }^{18}$.

La Sentencia del Tribunal Supremo de 8 de febrero de 1999 (TOL 14.763), aplica el artículo 15.2.b) para exonerar en el caso enjuiciado a los recurrentes de su responsabilidad en los hechos que se refieren a la inversión en activos no autorizados, actuación que se produce sin su conocimiento, adoptándose la misma fuera del Consejo de Administración.

17 En aplicación de esta Doctrina, la Sentencia de la Audiencia Nacional citada de 9 julio 1998 establece que "Es indudable que la pertenencia a un Consejo de administración, la simple titularidad del cargo, se traduce en una serie de potestades que se confieren a los nombrados, justamente para ser utilizadas en orden a prevenir situaciones como la enjuiciada; el descuido en el ejercicio de esas facultades, que aboca a la Sociedad a la comisión de una falta muy grave, implica un grado de negligencia o culpa para entender satisfecha, desde la óptica constitucional, la exigencia que dimana del art. 105 a) de la ley 24/1988".

18 En relación con la aplicación de la debida diligencia de los consejeros del artículo 127.1, véase igualmente la Sentencia de la Audiencia Nacional de 24 septiembre 1998 (TOL 137.276) con cita de sus sentencias anteriores de18 marzo 1998 y 18 junio 1998 con referencia a la Sentencia del TC 254/1993 sobre el principio de culpabilidad. 
Antes de tratar en el siguiente apartado relativo a las infracciones que se recogen en la Ley, comentaremos todo lo relativo a la compatibilidad de las sanciones administrativas y penales, y al principio “non bis in idem". El artículo 2 establece que el ejercicio de la potestad sancionadora es independiente de la posible concurrencia de delitos o faltas de naturaleza penal.

De conformidad con el principio "non bis in idem", íntimamente unido a los principios de legalidad y de tipicidad de las infracciones recogidas en el artículo 25 de la Constitución, y en el artículo 133 de la Ley 30/1992 sobre concurrencia de sanciones, el artículo 2 de la LDIEC establece la suspensión del expediente sancionador cuando se esté tramitando un proceso penal por los mismos hechos o por otros cuya separación de los que se dilucidan en el procedimiento sancionador sea racionalmente imposible. En el momento en que recaiga pronunciamiento firme de la autoridad judicial, se reanudará en su caso el expediente sancionador y la resolución administrativa deberá respetar la apreciación de los hechos de la resolución judicial.

Como recuerda la Sentencia del Tribunal Supremo de 12 de marzo de 1999 (TOL 137.222), y de conformidad con la jurisprudencia constitucional (STC n. ${ }^{\circ} 77 / 83$ ):

\begin{abstract}
"existe la regla de la subordinación de la actuación sancionadora de la Administración a la actuación de los Tribunales de Justicia y la primera no puede actuar mientras no lo hayan hecho los órganos jurisdiccionales, por lo que debe, en todo caso, respetarse, cuando actúe "a posteriori" el planteamiento fáctico que los tribunales hayan realizado, ya que, en otro caso, se produce un ejercicio del poder punitivo que traspasa los límites del artículo 25 de la Constitución y viola el derecho del ciudadano a ser sancionado sólo en las condiciones estatuidas por el referido precepto".
\end{abstract}

Para apreciar si se ha vulnerado o no el artículo 25 de la Constitución y los demás artículos de las normas citadas anteriormente, el Tribunal Supremo en la citada Sentencia de 12 de marzo de 1999 establece que deben tenerse en cuenta los siguientes criterios: a) existencia de plena identidad subjetiva entre el procedimiento sancionador y la causa penal instruida en el Tribunal competente y b) que la norma jurídica aplicada sea idéntica, ya que en muchos casos, como en el presente enjuiciado, la actuación penal persigue infracciones distintas tipificadas como delitos, a las obligaciones tipificadas como infracciones en las Leyes financieras.

Así, es muy frecuente que la actuación penal, como en el caso enjuiciado en esta Sentencia comentada, responda a la averiguación de hechos constitutivos de estafa, apropiación indebida y falsedad en documento mercantil, mientras que el expediente administrativo persigue la sanción del incumplimiento de obligaciones de garantía de la solvencia de las entidades financieras, tutelando los derechos de terceros, y defendiendo la prioridad de los intereses de los inversores sobre los de las entidades bursátiles.

Por otra parte, en muchas ocasiones la Jurisprudencia se pronuncia sobre las 268 frecuentes y reiteradas alegaciones de las demandas relativas a la vulneración del 
Concurso de infracciones por parte de la Resolución recurrida, regulado en el artículo 4.4 del Real Decreto 1398/1993 de 4 de agosto, por el que "cuando de la comisión de una infracción derive necesariamente la comisión de otra u otras, se deberá imponer únicamente la sanción correspondiente a la infracción más grave cometida". Así, las Sentencias establecen con rotundidad que para la aplicación del denominado Concurso medial se exige la necesaria derivación de unas infracciones respecto de las demás y viceversa, por lo que es indispensable que las unas no puedan cometerse sin ejecutar las otras.

La Sentencia del Tribunal Supremo de 17 de noviembre de 1998 (TOL 137.252), por ejemplo, establece con claridad que no se produce vulneración del mencionado concurso de infracciones en el caso enjuiciado de cuatro infracciones relativas a infracción del coeficiente de liquidez, infracción del límite de concentración de riesgos, simulación de transferencias de titularidad de fondos, e irregularidades contables. Las cuatro infracciones, señala la Sentencia, tienen una naturaleza autónoma "ya que para la consumación de las tres primeras no se requiere la práctica de irregularidades contables, que si además se lleva a cabo genera una nueva infracción, que no constituye un medio para cometer aquéllas, las cuales pueden ejecutarse sin ningún tipo de constatación en los libros de cuentas de la entidad".

Esta Sentencia resulta igualmente de indudable interés asimismo en relación con la aplicación del artículo 15 de la LDIEC relativo a la responsabilidad de los administradores y la debida diligencia que deben tener en el ejercicio de su cargo: "Esta actitud indiligente se produjo en el recurrente.... debía conocer la actividad desarrollada por ésta en el día a día y estaba obligado a decidirla, pese a lo cual abandonó completamente sus obligaciones, dejando que fuese otra persona la que tomara las decisiones, contribuyendo con su actitud omisiva a la realización de las mismas". No puede invocarse falta de participación en los hechos, señala la Sentencia, ni siquiera habiendo otra persona que haya declarado la autoría de los actos objeto de expediente, siendo de aplicación el art. 15.2, b), "por su cualidad de órgano ejecutor de las decisiones de la entidad, aun cuando otra persona declare la autoría de los actos objeto de expediente sancionador, pues al margen de ser posible en el ámbito sancionador supuestos de coautoría, es perfectamente compatible la conducta activa del confeso, con la omisiva y negligente del recurrente"

Por su parte, la Sentencia del Tribunal Supremo de 8 de febrero de 1999 (TOL 137.203) aplica igualmente la no existencia de Concurso medial del artículo 4.4 del Real Decreto 1398/1993 de 4 de agosto, en relación con un caso de comisión de varias infracción muy graves tipificadas en la Ley 46/1984, de 26 de diciembre, reguladora

19 La sanción del Consejo de Ministros consistió en multa de 18.030 euros y separación del cargo con inhabilitación durante seis años. La alegación sobre la no inscripción de su nombramiento en el Registro mercantil no se considera válida por parte del Tribunal para exonerarle de responsabilidad puesto que había aceptado el cargo de Consejero de la entidad, Director general encargado de las operaciones de la entidad, y miembro del Comité interno de Dirección, siendo ajeno a todo ello el problema jurídico acerca de la naturaleza de la inscripción en el Registro mercantil. 
de las Instituciones de Inversión Colectiva. La Sentencia establece que no existe concurso de infracciones "al poder ejecutarse la simulación de transferencias, la falsedad en la contabilidad, la inversión en activos distintos a los autorizados legalmente, y el peligro a los intereses de los partícipes en los fondos, con total independencia"20.

\section{Infracciones}

Las infracciones a la presente Ley se clasifican en muy graves, graves y leves, según establece el art. 3, tipificándose las muy graves en el art. 4, las graves en el art. 5 y las leves en el art. 6. Para las leves establece una cláusula genérica como las "infracciones de preceptos de normas de ordenación o disciplina que no constituyan infracción grave o muy grave".

\section{A) Infracciones muy graves}

Las infracciones muy graves se enumeran en 17 apartados, desde la letra a) hasta la p), habiendo sido incorporadas muchas de ellas posteriormente en sucesivas Leyes o modificadas con respecto a su redacción inicial. Dentro de estos apartados, destacamos los siguientes que son objeto, por otra parte, de un mayor número de Sentencias con comentario o cita de las más relevantes:

a) La realización de determinadas actuaciones, actos y contratos que se relacionan a continuación sin la autorización preceptiva, sin observar las condiciones fijadas en la misma, o habiéndola obtenido por medio de declaraciones falsas o por otro medio irregular. Estas situaciones se relacionan con: 1. Fusiones, absorciones o escisiones de entidades de crédito; 2 . Adquisición de acciones u otros títulos representativos de capital, o cesión de sus derechos políticos; 3. Distribución de reservas, expresas u ocultas; 4. Apertura de oficinas operativas en el extranjero por parte de entidades de crédito españolas.

b) El mantener durante un periodo de seis meses unos recursos propios inferiores a los exigidos para obtener la autorización correspondiente al tipo de entidad de crédito de que se trate.

Así, destacamos las Sentencias del Tribunal Supremo de 1 de febrero de 1999 (TOL 14.760), y de 18 de octubre de 2006 (TOL 1.009.688).

20 En esta Sentencia, se declara por otra parte la retroacción de las actuaciones en relación con una de las sanciones relativa a la separación del cargo con inhabilitación durante diez años, que se anula por el momento, al existir un proceso penal pendiente, con el fin que la Administración espere a la sentencia firme quedando vinculada por los hechos, sobre la participación o no del citado cargo en 270 las infracciones, que se declaren probados por el órgano judicial penal en relación con la citada sanción 
La Sentencia de 18 de octubre 2006 citada, en relación con esta infracción analiza los efectos de una ampliación de capital y el plazo exigido de los seis meses. Los datos son que la entidad se encontraba por debajo de lo exigido legalmente para dotación de recursos propios desde junio 2002 y que realiza una ampliación de capital en diciembre superados los seis meses, que además no se inscribe hasta marzo 2003. Con estos antecedentes, la Sentencia confirma la sanción no aceptando la alegación de que el retraso se debió al órgano supervisor:

\begin{abstract}
"Ante esta afirmación la posible superación del mínimo por la ampliación de capital no puede acogerse cuando esa ampliación no había sido llevada a cabo materialmente, pues no puede considerarse como tal, ni tiene efecto interruptivo, la que se realiza de forma parcial y tardía. Ni puede considerarse que ello fuese debido a circunstancias imputables al órgano supervisor, cuando éste realiza el control de estas operaciones dentro de los procedimientos y con arreglo a las facultades que le confiere su normativa reguladora, máxime si se presenta en un momento en el que es fácil entender que no se iba a resolver en un tiempo suficiente".
\end{abstract}

c) Incurrir en insuficiente cobertura del coeficiente de recursos propios mínimos, cuando éstos se sitúen por debajo del 80 por ciento del mínimo establecido reglamentariamente en función de los riesgos asumidos, o por debajo del mismo porcentaje exigido por el Banco de España, permaneciendo en esa situación por un período, al menos, de seis meses.

Así, entre otras, las Sentencias del Tribunal Supremo de 21 de abril de 1997 (TOL 194.045), 19 de junio de 1997 (TOL 194.891), 7 de julio de 1997 (TOL 194.608) y 18 de octubre de 2006 (TOL 1.009.688).

La Sentencia del Tribunal Supremo de 7 de julio de 1997 (TOL 194.608) recuerda en relación con esta infracción que no cabe entrar en valoraciones como alega el recurrente sobre inexistencia de perjuicios ya que "El riesgo que para los depositantes en particular y para la estabilidad del sistema financiero en general conlleva el incumplimiento de las normas sobre recursos propios está explícitamente reconocido en la exposición de Motivos de la L.D.", ni es admisible el argumento que la Circular 19/1989 el Banco de España es de confusa interpretación, "pues -como también dijimos contestando a un alegato semejante en la sentencia de 21 de abril de 1997, fundamento jurídico cuarto- las posibles dudas pudieron ser fácilmente despejadas acudiendo a la Oficina de Instituciones Financieras del B.E., a la que la norma decimotercera de la indicada Circular encomienda cabalmente la resolución de las dudas que su interpretación pudiera originar".

La Sentencia del Tribunal Supremo de 19 de junio 1997 (TOL 194.891), frente a la alegación de los demandantes de no infracción, señala que en el procedimiento seguido está acreditado y así se recoge en la resolución sancionadora que "cuando la inspección del Banco de España advirtió a la entidad sobre las dudas que ésta tenía en orden a la interpretación de la norma 13 de la Circular 19/89, la citada entidad mercantil 
amplió el capital y vendió determinados inmuebles; pero la empresa siguió presentando déficit de recursos propio al 30 de junio de 1992, equivalente al 207\% de los mínimos necesarios. Estos hechos aparecen claramente tipificados y sancionados en la Ley 26/1988, arts 4c) y 12.a)".

e) La realización de actos u operaciones prohibidas por normas de ordenación y disciplina con rango de ley o con incumplimiento de los requisitos establecidos en las mismas, salvo que tenga un carácter meramente ocasional o aislado.

Así, entre otras, las Sentencias del Tribunal Supremo de 1 de febrero de 1999 (TOL 14.760) y de 8 de abril de 2008 (TOL 1.311.761).

La Sentencia del Tribunal Supremo de 8 de abril de 2008 (TOL 1.311.761), enjuicia la resolución sancionadora al Director general de la Caja Rural de Alicante Sociedad de Cooperativa de Crédito en relación con la infracción de este apartado e) del artículo 4 de la Ley de Disciplina en relación con el artículo 60.3 de la Ley General de Cooperativas y el 9.8 d) de la Ley de Cooperativas de Crédito por la que se le impuso la sanción de inhabilitación para ejercer cargos de administración o dirección en cualquier entidad de crédito por un plazo de 5 años y multa de 36.060,73 euros, previstas en los apartados a) y d) del art. 12 de la Ley de Disciplina. La Sentencia después del análisis conjunto de las tres Leyes concluye que "entra dentro de la dirección del "tráfico empresarial ordinario" de la entidad el velar porque se protejan los intereses de las mismas, lo que incluye, como es obvio, el que no se incumplan las obligaciones como las relativas a las incompatibilidades del personal directivo", por lo que confirma la resolución sancionadora del Ministro de Economía. La Sentencia cita diversos antecedentes jurisprudenciales en relación con la misma materia de gran interés ${ }^{21}$.

f) Carecer de la contabilidad exigida legalmente o llevarla a cabo con irregularidades esenciales que impidan conocer la situación patrimonial y financiera de la entidad o del grupo consolidable o conglomerado financiero al que pertenezcan.

Así, destacamos las Sentencias del Tribunal Supremo de 2 de febrero de 1998 (TOL 12.968) y de 7 de febrero de 2003 (TOL 253.712).

21 Así, señala la Sentencia citada de 8 de abril 2008 que: "Este Tribunal ha dictado una serie de sentencias en relación con el tema planteado que dan respuesta a cuestiones objeto de controversia en el presente caso. En este sentido puede citarse la de 15 de noviembre 2004 (rec. n. ${ }^{\circ}$ 119/2002 que afectaba a los miembros del Consejo Rector de la Caja, y que confirmó la sanción impuesta a los mismos declarando aplicable a la Caja la Ley 13/1989 dada su condición de entidad de crédito. La de 18 de noviembre 2004 (rec. n. ${ }^{\circ}$ 122/2002) por la que se confirmó la sanción impuesta al Presidente del Consejo Rector, y en la que se tuvieron por acreditados los hechos que dieron lugar a la imposición de la sanción por la Orden impugnada, la aplicación a este caso de la Ley 26/1988 a la vista de su artículo 1.2, pues la Caja es una entidad de crédito y la declaración de que la prohibición del art. 9.8 d) de la Ley le incumbe pues también está dirigida a las Cooperativas que mantienen a directivos con las incompatibilidades señaladas. La deuda es vencida y exigible, los apuntes contables son ficticios y la reiteración de la conducta y la desatención a los requerimientos del Banco de España permite concluir 272 que no se tata de una actuación aislada. Finalmente, la de 7 de diciembre 2002 (rec. $\left.n .^{\circ} 94 / 2002\right)$ por la que se confirmó en términos muy similares la sanción impuesta directamente a la Caja."(F.J. 1. ' y2. ${ }^{\circ}$ )". 
La Sentencia del Tribunal Supremo de 2 de febrero de 1998 (TOL 12.968), recuerda la importancia de la actividad de las entidades de crédito que reciben dinero de muchas personas por lo que es totalmente necesario un régimen especial de supervisión mucho más intenso que el de otros sectores económicos para lo que resulta imprescindible que la autoridad supervisora conozca en todo momento la situación patrimonial y financiera de las mismas:

"La especial actividad que desarrollan estas entidades de crédito... pone de relieve, como indica la Exposición de Motivos de la Ley 26/1988, la absoluta necesidad de someter las Entidades Financieras a un régimen especial de supervisión administrativa en general, mucho más intenso que el que soporta la mayoría de los restantes sectores económicos... La opacidad en un momento dado es la que se castiga en el artículo 4 f) de la ley Disciplinaria, y es evidente que la misma se ha producido, en la fecha de la inspección, sin que arrepentimientos o correcciones posteriores sirvan para eludir la correcta calificación que se ha hecho en el acto impugnado".

La Sentencia del Tribunal Supremo de 7 de febrero 2003 (TOL 253.712) en recurso de casación contra la Sentencia de la Audiencia Nacional de 15 de abril de 1997, caso Banco Ibercorp, tiene por objeto las resoluciones por las que se impone al Director General del Banco la sanción de separación del cargo con inhabilitación para ejercer en cualquier entidad de crédito por un plazo de tres años, más multa. En esta Sentencia, el Tribunal Supremo rechaza el argumento del recurrente relativo al carácter subsidiario de la responsabilidad de los administradores y directivos de las entidades bancarias -ante la no imposición a la Entidad de sanción alguna en este caso-, declarando el Tribunal Supremo que dicha responsabilidad no es subsidiaria sino todo lo más concurrente, sin perjuicio como en el caso presente "que la concurrencia de factores de diversa naturaleza imponga o aconseje excluir de la sanción a la sociedad y limitarla a sus directivos o administradores". Así, en ocasiones, como en el caso enjuiciado, y con el fin de no agravar la difícil situación económica de la entidad y con ello perjudicar más todavía a terceros, como razona la Administración y argumenta la sentencia de instancia de la Audiencia Nacional, el Tribunal Supremo declara que “...consideraciones de otro tipo, relativas a la evitación de daños a terceros, aconsejen no agravar aún más la situación financiera de entidades de crédito ya en dificultades, exonerándoles de la sanción correspondiente pese a que su conducta fuera a ella acreedora, declarada que ha sido la comisión de una determinada infracción en materia de disciplina bancaria".

h) La negativa o resistencia a la actuación inspectora, siempre que medie requerimiento expreso y por escrito al respecto.

Sobre la interpretación de los conceptos indeterminados "negativa” y "resistencia" a la actuación inspectora, véase la Sentencia del Tribunal Supremo de 18 de octubre de 2006(TOL 1.009.688) en la que se incluyen en dichos conceptos, actuaciones probadas de actitud "sólo formalmente colaboradora" y/o "resistencia más o menos pasiva" por el no envío de documentación requerida o envío incompleto y el retraso 
de documentación en plazo de documentos de fácil aportación para la entidad. La Sala señala además que "Debe recordarse, por último, que frente a las afirmaciones efectuados por la actora, las realizadas por la autoridad inspectora cuentan con el valor probatorio a que se refiere el artículo 17.5 del Reglamento sobre el Procedimiento para el ejercicio de la potestad sancionadora supletoriamente aplicable (Real Decreto 1398/1993 de 4 de agosto)".

i) La falta de remisión al órgano administrativo competente de cuantos datos o documentos deban remitírsele o requiera en el ejercicio de sus funciones, o su falta de veracidad, cuando con ello se dificulte la apreciación de la solvencia de la entidad o la del grupo consolidable o conglomerado financiero a que pertenezca.

La Sentencia del Tribunal Supremo de 7 de julio de 1997 (TOL 194.608) aprecia la existencia de esta infracción muy grave en razón de la falta de remisión de datos a la Central de información de riesgos del Banco de España. Frente a la alegación del recurrente de las dificultades de interpretación de la Circular 7/1989 que contiene las normas sobre las declaraciones a dicha Central y que la ausencia parcial de remisión de datos no han dificultado la apreciación de la solvencia de la entidad, la Sentencia declara que la no declaración y remisión de datos afectaba en total a 1.625 millones de riesgos no declarados, que comprendían los efectos impagados, los morosos, los dudosos y las reinstrumentaciones de impagados que se contabilizaban como "deudores por leasing", por lo que:

"Sostener, como hace el actor que no declarar riesgos directos por 1.625 millones que representan el $34 \%$ del riesgo declarable, no dificulta la apreciación de la solvencia de la empresa es un argumento carente de fundamento objetivo que si más debe ser rechazado. Téngase en cuenta que la solvencia de una entidad como M.S.A. depende, entre otras cosas, de la calidad de los riesgos y, por tanto, no puede medirse aquélla si no se conocen perfectamente estos, razón por la cual la falta de remisión de tales datos, imprescindibles para valorar la solvencia de la entidad, constituye la infracción muy grave por la que ha sido sancionada".

j) El incumplimiento del deber de veracidad informativa debida a sus socios, a los depositantes, prestamistas, y al público en general, así como el incumplimiento del deber de confidencialidad sobre los datos recibidos de la Central de información de riesgos, su uso para fines diferentes de los previstos en la Ley, o la solicitud de informes sobre personas titulares de riesgos fuera de los casos expresamente autorizados en la Ley. Todo ello, siempre que, por el número de afectados o por la importancia de la información, tales incumplimientos puedan estimarse como especialmente relevantes.

La Sentencia del Tribunal Supremo de 18 de octubre de 2006 (TOL 1.009.688) establece en relación con esta infracción que en el presente caso: 
"inversión creciente" la naturaleza de "depósito", cuando lo que realmente se estaba contratando era una póliza de seguros de otra entidad distinta que Eurobank se limitaba a comercializar. La trascendencia de esta operación viene determinada por el número de clientes a los que afectó y a los que llegó la información mediante el sistema de banca telefónica, que se pone de manifiesto en el expediente, en los que además resalta el carácter seguro de la operación, que en determinados casos se realizó sin mediar autorización de los clientes".

I) El adquirir participaciones significativas o aumentarlas infringiendo lo previsto en el Título VI de esta Ley.

m) Las infracciones graves cuando durante los cinco años anteriores a su comisión hubiera sido impuesta a la entidad de crédito sanción firme por el mismo tipo de infracción.

Sentencia del Tribunal Supremo de 18 de octubre de 2006 (TOL 1.009.688), en relación con la reincidencia en la infracción grave del artículo 5 k) de la Ley relativa a la insuficiente dotación de las previsiones para insolvencias, habiéndole sido impuesta sanción firme a la misma entidad en los cinco años anteriores. Esa Sentencia establece en relación con la trascendencia e importancia de esta infracción en relación con los bancos y sus clientes depositantes de fondos que:

\begin{abstract}
"Esto es especialmente sensible en la materia de dotación de las previsiones para insolvencias, que afectan a la propia naturaleza del negocio bancario, cuya base la constituyen los fondos depositados por los impositores, y cuya retirada debe serles permitida en cualquier momento que lo deseen, de tal forma que para evitar una política de créditos arriesgada o un reparto inadecuado de beneficios, las indicadas dotaciones evitarán la no devolución de los depósitos cuando les fueren reclamados por los depositantes. Precisamente por ello, los miembros del Consejo de Administración tienen que poner una especial diligencia en comprobar que estas dotaciones se encuentran realizadas, y contrastarlas con los créditos que por sí mismos deben calificar como dudosos. Y ello no es exclusivamente imputable a comisiones delegadas, consejeros delegados o directores generales -art. 15.2.b) LDIEC-, sino que por la propia esencialidad a que se ha aludido es misión relevante de todo el Consejo de Administración, sin que para su cumplimiento se requieren especificos conocimientos, sino que bastan los que se exigen a los que voluntariamente han asumido ser miembros de dicho Consejo".
\end{abstract}

\title{
B) Infracciones graves
}

Las infracciones graves se enumeran en el artículo 5, en 23 apartados desde la letra a) hasta la w). El apartado de la letra g) ha sido derogado por la Ley 12/1998, de 28 de abril.

Dentro de estos apartados, destacamos a continuación, al igual que hemos hecho en el apartado anterior los siguientes con referencia a las sentencias sobre los mismos: 
a) La realización de actos u operaciones sin autorización, cuando ésta sea preceptiva, sin observar las condiciones básicas de la misma, u obtenerla por medio de declaraciones falsas o por otro medio irregular, salvo en los casos en que ello suponga la comisión de una infracción muy grave de acuerdo con lo previsto en el artículo anterior.

Así, destacamos las Sentencias del Tribunal Supremo de 7 de abril 1999 (TOL 22.484) y de 11 de marzo 1998 (TOL 12.969).

La Sentencia del Tribunal Supremo de 7 de abril 1999 (TOL 22.484), confirma la sanción impuesta por la infracción grave consistente en la captación de fondos por parte de la entidad mediante cuentas financieras para su inversión en pagarés del tesoro, cuyos contratos no habían sido autorizados por la Dirección General del Tesoro y Política Financiera, habiéndose probado que estas prácticas, por importe superior a seis millones de euros, tuvieron lugar durante el tiempo que el demandante era Vocal del Consejo de administración. Igualmente la Sentencia del Tribunal Supremo de 11 de marzo 1998 (TOL 12.969), confirma la sanción impuesta frente a la alegación de la demanda consistente en que el tipo descrito en el apartado a) del artículo 5 no pude servir de cobertura para sancionar cualquier acto realizado sin previa autorización al margen de la entidad o importancia del mismo. La Sentencia, en primer lugar manifiesta que la actora entiende que la falta de autorización respecto del modelo de contrato a utilizar con los clientes para la realización de inversiones en Pagarés del Tesoro no reviste la gravedad necesaria para calificar la conducta como falta grave. Bien al contrario de esta alegación, a continuación declara que:

"Debe tenerse, por otra parte, presente que, como se desprende del artículo 48.2 de la Ley Disciplinaria, la finalidad de que los contratos se formalicen por escrito y con el cumplimiento de unos requisitos muy rigurosos, nace de la necesidad de proteger los legítimos intereses de la clientela activa y pasiva de las entidades de crédito. De aquí deriva la gravedad del incumplimiento de estos requisitos, por la trascendencia que puede tener respecto de intereses de terceros, como de hecho se puso de manifiesto en el presente supuesto, al quedar estos fondos durante 108 días sin invertir en los activos previstos".

e) La realización de actos u operaciones con incumplimiento de las normas dictadas al amparo del número 2 del artículo 48 de esta Ley. Estas normas se refieren a diversos actos u operaciones de las entidades de crédito con sus clientes que son aprobadas por el Ministerio de Economía y Hacienda con el fin de proteger los intereses de la clientela, activa y pasiva, principalmente en materia de contratación de los servicios que se van a prestar.

Así, las Sentencias del Tribunal Supremo de 2 de febrero de 1998 (TOL 12.968) y de 25 de octubre 2000 (TOL 139.497).

La Sentencia del Tribunal Supremo de 2 de febrero de 1998 (TOL 12.968), trata la conducta, que se incardina en el presente apartado, de no facilitar a los clientes nin276 gún documento con motivo de la liquidación de intereses y comisiones practicadas: 
"Alega la entidad recurrente falta de concreción de los hechos imputados, y efectuarse todas las operaciones mediante escrituras ante notario, con la garantía que ofrece la fe pública notarial. Tales alegaciones deben rechazarse al reconocer la propia actora en su demanda que los pertinentes detalles de liquidación a los clientes se facilitaban en la mayoría de las operaciones realizadas. Es en relación con ese resto a los que no se informaba, al que hay que reconducir la infracción, pues el artículo 48 impone el deber de información en todas las operaciones".

i) El incumplimiento de las normas vigentes en materia de límite de riesgos o de cualquier otra que imponga limitaciones cuantitativas, absolutas o relativas, al volumen de determinadas operaciones activas o pasivas.

Así, las Sentencias del Tribunal Supremo de 21 de abril de 1997 (TOL 194.045), 19 de junio 1997 (TOL 194.891), 2 de febrero de 1998 (TOL 12.968) y 25 de octubre 2000 (TOL 139.497).

La Sentencia del Tribunal Supremo de 19 de junio 1997 (TOL 194.891) recuerda al demandante ante su alegato relativo a que, en primer lugar, se le imponen sanciones como consecuencia de actos dolosos, pese a que -argumenta-que siempre actuó de buena $\mathrm{fe}$, y a que, en segundo lugar, a que aún admitiendo que los hechos imputados sean ciertos ello se debió a un error de interpretación de las normas aplicables y no a la mala fe, que "Por ser sanciones graves, son sancionadas en la Ley tanto si se imputan a conducta dolosa como a conducta negligente (art. 15.1 de la citada Ley); pues bien, la Ley castiga a quienes ejerciendo cargos de administración o dirección, cometan infracciones graves con alguna de las siguientes sanciones....".

La Sentencia del Tribunal Supremo de 2 de febrero de 1998 (TOL 12.968), en relación con esta infracción relativa al incumplimiento de las normas vigentes en materia de límite de riesgos, sanciona la concesión por parte de la infractora de un crédito al promotor de un edificio por un importe que supone el 40,6\% de los recursos propios computables declarados a fin del ejercicio de 1992 con infracción de lo establecido en el Real Decreto 1370/1985. La entidad infractora pretende alegar que dicho préstamo no constituye una sola operación sino varias operaciones al referirse a diversos apartamentos, y que en cualquier caso ello constituiría simplemente una cuestión de interpretación distinta a la de la autoridad supervisora. Sin embargo, la Sentencia recuerda a la entidad que:

"Se pretende enmascarar la ausencia de culpabilidad en una ignorancia excusable. Esto no puede predicarse de una institución de crédito, conocedora de cómo se actúa en el mercado inmobiliario. Al otorgarse el crédito hipotecario al promotor como tal, hasta tanto no se produzca su división entre los apartamentos construidos y subsiguiente subrogación de los adquirentes, ha de ser considerada como una sola operación. La propia entidad, ante la solicitud de aclaración que se solicita por el Instructor del expediente, reconoce en su escrito de 28 de marzo de 1994 que la inscripción individual se paralizó, y obvio es decir que sin inscripción individual no hay hipoteca, por ser la inscripción constitutiva de ese derecho". 
j) El incumplimiento de las condiciones y requisitos exigidos por la normativa correspondiente en las operaciones crediticias que gocen de subvención de intereses u otras ayudas públicas.

k) La dotación insuficiente de las reservas obligatorias y de las previsiones para insolvencias.

Así, destacamos las Sentencia del Tribunal Supremo de 21 de abril de 1997 (TOL 194.045), 7 de julio de 1997 (TOL 194.608), 11 de marzo 1998 (TOL 12.969), y 7 de abril 1999 (TOL 22.484).

I) La falta de remisión al órgano administrativo competente de los datos o documentos que deban remitírsele o que el mismo requiera en el ejercicio de sus funciones, así como la falta de veracidad en los mismos, salvo que ello suponga la comisión de una infracción muy grave. A los efectos de lo dispuesto anteriormente, se entenderá que hay falta de remisión cuando la misma no se produzca dentro del plazo concedido al efecto por el órgano competente al recordar por escrito la obligación o reiterar el requerimiento.

Así, las Sentencias del Tribunal Supremo de 21 de abril de 1997 (TOL 194.045), 11 de marzo 1998 (TOL 12.969), 1 de febrero de 1999 (TOL 14.760), 7 de abril 1999 (TOL 22.484) y 25 de octubre 2000 (TOL 139.497).

p) El incumplimiento de las normas vigentes sobre contabilización de operaciones y sobre formulación de balances, cuentas de pérdidas y ganancias y estados financieros de obligatoria comunicación al órgano administrativo competente.

El Tribunal Supremo manifiesta reiteradamente en relación con este apartado que la infracción de las Circulares del Banco de España que contienen estas normas técnicas "equivale para las entidades y sus Consejeros a la infracción de normas, debido a la relación de sujeción especial que las entidades de crédito mantienen respecto a aquella institución”. Así, entre otras, las Sentencias del Tribunal Supremo de 21 de abril de 1997 (TOL 194.045), 7 de julio de 1997 (TOL 194.608), 19 de junio 1997 (TOL 194.891), 2 de febrero de 1998 (TOL 12.968), 11 de marzo 1998 (TOL 12.969), 1 de febrero de 1999 (TOL 14.760), 7 de abril 1999 (TOL 22.484) y 25 de octubre 2000 (TOL 139.497).

q) Las infracciones leves, cuando durante los dos años anteriores a su comisión hubiera sido impuesta a la entidad de crédito sanción firme por el mismo tipo de infracción.

Además, la Disposición adicional primera de la Ley establece como infracción grave la vulneración del deber de guardar reserva de las informaciones relativas a los saldos, posiciones, transacciones y demás operaciones de sus clientes sin que las mis278 mas puedan ser comunicadas a terceros u objeto de divulgación. Este deber de reser- 
va se exceptúa en los casos en que, o bien el cliente o bien las leyes permitan su comunicación o divulgación a terceros, o que en su caso les sean requeridas o hayan de remitir a las autoridades de supervisión.

\section{C) Infracciones leves}

En relación con las infracciones leves, como ya hemos comentado, el artículo 6 no establece una tipificación enumerativa de las mismas sino que dispone con carácter general que son "aquellas infracciones de preceptos de obligada observancia para las entidades de crédito comprendidos en normas de ordenación o disciplina que no constituyan infracción grave o muy grave conforme a lo dispuesto en los dos artículos anteriores".

Así, entre otras, la Sentencia del Tribunal Supremo de 7 de julio de 1997 (TOL 194.608) por infracción consistente en la no remisión a la Central de Información de Riesgos del Banco de España de las declaraciones mensuales correspondientes a los riesgos vivos, rebajándose de grave a leve en la propia resolución sancionadora al no existir requerimiento escrito; y la Sentencia de 1 de febrero de 1999 (TOL 14.760) por infracciones consistentes en la realización de operaciones con no residentes con incumplimiento de la normativa vigente y en la existencia de irregularidades relativas a transparencia de las operaciones y protección de la clientela.

\section{D) Prescripción de infracciones}

Se establece un plazo de prescripción específico en relación con el régimen general dispuesto en el artículo 132.1 de la Ley 30/1992. Así, el artículo 7 de esta LDIEC dispone que las infracciones muy graves y las graves prescribirán a los cinco años, en un plazo mucho más amplio que el régimen general de la Ley 30/1992 de tres años y de dos años respectivamente, mientras que las infracciones leves prescriben a los dos años frente a los seis meses del régimen general.

Mientras el artículo 7.2 establece la misma regulación que el artículo 132.2 de la Ley 30/1992 con respecto a la fecha del “dies a quo", que será la fecha en que la infracción hubiera sido cometida, con la matización que en las infracciones derivadas de una actividad continuada la fecha inicial del cómputo es la de finalización de la actividad o la del último acto en que la infracción se consume, el artículo 7.3 establece una importante diferenciación con el régimen general en relación con el momento en que vuelve a correr el plazo si ha habido interrupción.

En este caso, en el que se ha interrumpido la prescripción por la iniciación del procedimiento sancionador con conocimiento del interesado, el plazo volverá a correr si el expediente permaneciera paralizado durante seis meses por causa no imputable al mismo, con un manifiesto perjuicio al interesado en relación al régimen general que establece un plazo, mucho menor, de un mes. 


\section{Sanciones}

La Ley establece un régimen de sanciones dual referido, por una parte, a las Entidades infractoras y, de otra, a los cargos de administración o dirección de las mismas como ya hemos comentado en el apartado primero sobre las características generales de la Ley.

\section{A) Entidades}

En primer lugar, las Entidades infractoras serán objeto de las siguientes sanciones establecidas en los artículos 9 a 11 y que podemos agrupar en cuatro tipos: multa pecuniaria, revocación de la autorización de la entidad, amonestación pública con publicación en el BOE, y amonestación privada. La Ley establece para cada tipo de infracción varias sanciones pudiendo imponerse una o varias en el caso de las infracciones muy graves o graves. Para la determinación del abanico de posibilidades de sanciones que se establece, así como la cuantía de la infracción en el caso de multa, la propia Ley en el artículo 14 recoge una serie de criterios con el fin de respetar el principio general sancionador de proporcionalidad.

Las infracciones muy graves serán sancionadas por una o más de las siguientes sanciones: a) Multa por importe de hasta el 1 por 100 de sus recursos propios, o hasta 300.000 euros si dicho porcentaje fuera inferior a esta cantidad; b) Revocación de la autorización de la entidad. Dicha sanción será sustituida por la prohibición de iniciar nuevas operaciones para aquellas sucursales de entidades de crédito autorizadas por otro Estado miembro de la UE; y c) Amonestación pública con publicación en el BOE.

Las infracciones graves serán sancionadas por una o más de las siguientes sanciones: a) Multa por importe de hasta el 0,5 por 100 de sus recursos propios, o hasta 150.000 euros si dicho porcentaje fuera inferior a esta cantidad; y b) Amonestación pública con publicación en el BOE. Las infracciones leves serán sancionadas por una de las siguientes sanciones: a) Multa por importe de hasta 60.000 euros, o b) Amonestación privada.

Como hemos comentado, el abanico de sanciones que puede imponer la Resolución debe responder a una serie de criterios que la Ley establece para las infracciones de las entidades en el apartado 1 de su artículo 14, y que son los siguientes: a) La naturaleza y entidad de la infracción. b) La gravedad del peligro ocasionado o del perjuicio causado. c) Las ganancias obtenidas, en su caso, como consecuencia de los actos u omisiones constitutivos de la infracción. d) La importancia de la entidad de crédito correspondiente, medida en función del importe total de su balance. e) Las consecuencias desfavorables de los hechos para el sistema financiero o la economía nacional. f) La circunstancia de haberse producido a la subsanación de la infracción por propia iniciativa. g) En el caso de insuficiencia de recursos propios, las dificultades

280 objetivas que puedan haber concurrido para alcanzar o mantener el nivel legalmente 
exigido. h) La conducta anterior de la entidad en relación con las normas de ordenación y disciplina que le afecten, atendiendo a las sanciones firmes que le hubieran sido impuestas durante los últimos cinco años.

Son abundantes las Sentencias en donde se trata la cuestión alegada por los demandantes relativa a la legalidad de la elección de las sanciones impuestas en la resolución sancionadora así como la legalidad de la graduación de las sanciones elegidas en cuanto al principio de proporcionalidad y los criterios establecidos en el artículo 14 de la LDIEC. Así, la Sentencia del Tribunal Supremo de 12 de marzo 1999 (TOL 137.222) que dispone la legalidad de las sanciones elegidas impuestas en el presente caso en función de "la gravedad de los hechos cometidos así como la importancia de los bienes jurídicos protegidos......", así como la legalidad de la graduación de las sanciones en su grado máximo que se ha resuelto ".. no de manera discrecional, sino teniendo en cuenta todas las circunstancias mencionadas, por lo que se ha considerado que las sanciones a imponer deben serlo en su grado máximo".

La Sentencia del Tribunal Supremo de 7 de julio de 1997 (TOL 194.608) que detalladamente rechaza los argumentos del recurrente sobre vulneración de la aplicación de los criterios del artículo 14, "sin que sea posible acudir a ninguno de los criterios recogidos en los apartados a) al h) de aquel artículo para obtener una reducción", y recuerda finalmente al recurrente en relación con el criterio del apartado f) relativo a haber procedido a la subsanación de la infracción por propia iniciativa que, "hemos de destacar que, en nuestro caso, la subsanación fue precedida del requerimiento del B.E.".

La Sentencia del Tribunal Supremo de 14 de noviembre de 2006 (TOL 1.018.850) que en una detalladísima sentencia sobre diversas cuestiones, en relación con varias sanciones por infracciones muy graves impuestas por el Consejo de Ministros a una sociedad de tasación y a varios cargos de la misma, dispone en relación con el principio de proporcionalidad y los criterios que establece el artículo 14 de la LDIEC que el Consejo de Ministros ha respetado en este caso las directrices jurisprudenciales sobre el principio de proporcionalidad establecidas en la Sentencia de esa Sala de 24 de mayo de 2004 (RC 7600/2000):

"Pues, en efecto, el principio de proporcionalidad, en su vertiente aplicativa ha servido en la jurisprudencia como un importante mecanismo de control por parte de los Tribunales del ejercicio de la potestad sancionadora de la Administración, cuando la norma establece para una infracción varias sanciones posibles o señala un margen cuantitativo para la fijación de la sanción pecuniaria; y, así, se viene insistiendo en que el mencionado principio de proporcionalidad o de la individualización de la sanción para adaptarla a la gravedad de hecho, hacen de la determinación de la sanción una actividad reglada y, desde luego, resulta posible sen sede jurisdiccional no sólo la confirmación o eliminación de la sanción impuesta sino su modificación o reducción".

Igualmente, la Sentencia del Tribunal Supremo de 1 de julio de 2008 (TOL 1.347.021), ante la alegación de la recurrente de vulneración del principio de pro- 
porcionalidad en relación con la falta de intencionalidad, reiteración o reincidencia, así como la ausencia de perjuicios a clientes o terceros, manifiesta la legalidad de la resolución sancionadora no apreciándose desproporción en su importe ya que "del examen de los hechos se pone de manifiesto que han concurrido circunstancias que tanto permitían agravar como atenuar la sanción de acuerdo con el artículo 131 de la LPAC y 14 de la Ley de Disciplina e Intervención de Entidades de Crédito, pues frente a la falta de reincidencia y de perjuicios, la intencionalidad de las conductas, en cuanto plus de responsabilidad, permitían disminuir el efecto reductor de aquellas atenuantes".

\section{B) Cargos de Administración y Dirección}

En segundo lugar, los artículos 12, 12 bis y 13 establecen las sanciones que pueden imponerse a los cargos de administración, de hecho o de derecho, de las entidades, que sean responsables de la comisión de infracciones muy graves y graves. Estas sanciones son independientes de las que corresponda imponer a la entidades y que ya hemos comentado anteriormente.

Las infracciones muy graves podrán ser sancionadas, de conformidad con el artículo 12, con las sanciones siguientes: a) Multa a cada uno de ellos por importe no superior a 150.000 euros; b) Suspensión en el ejercicio del cargo por plazo no superior a tres años; c) Separación del cargo, con inhabilitación para ejercer cargos en la misma entidad de crédito por un plazo máximo de cinco años; d) Inhabilitación para ejercer cargos de administración o dirección en cualquier entidad de crédito o del sector financiero, con separación en su caso del cargo que ocupe el infractor en una entidad, por plazo no superior a diez años. En el presente caso, se trata de sanciones alternativas por lo que en su apartado $2 .^{\circ}$ este artículo establece la compatibilidad de la sanción de multa de la letra a) con las sanciones previstas en las letras c) y d) relativas a la separación e inhabilitación.

Las infracciones graves podrán ser sancionadas, de conformidad con el artículo 13, con las sanciones siguientes: a) Amonestación privada; b) Amonestación pública; c) Multa a cada uno de ellos por importe no superior a 90.000 euros; d) Inhabilitación para ejercer cargos de administración o dirección en cualquier entidad de crédito o del sector financiero, con separación en su caso del cargo que ocupe el infractor en una entidad, por plazo no superior a un año. En el presente caso, se establece a continuación la compatibilidad de la sanción de multa de la letra c) con la sanción prevista en la letra d) relativa a la separación e inhabilitación.

En aplicación de los artículos 12 y 13, destacamos las Sentencias del Tribunal Supremo de 21 de abril de 1997 (TOL 194.045), 19 de junio de 1997 (TOL 194.891), 11 de marzo 1998 (TOL 12.969), 1 de febrero de 1999 (TOL 14.760), 7 de abril 1999 (TOL 22.484), 25 de octubre 2000 (TOL 139.497), 17 de enero 2002 (TOL 129.600), 18 de 282 octubre de 2006 (TOL 1.009.688) y 8 de abril de 2008 (TOL 1.311.761). 
La Sentencia del Tribunal Supremo de 21 de abril de 1997 (TOL 194.045) lleva a cabo una interesante argumentación en relación con la interpretación y aplicación de los artículos 12 y 13 relativos a las facultades del órgano competente para dictar la resolución sancionadora, en el presente caso el Consejo de Ministros sobre infracción grave, en relación con la posibilidad que tiene de elección de la sanción a imponer, sin estar vinculado por la propuesta de resolución en cuanto a la sanción propuesta, y siempre que no altere la gravedad de la infracción sancionada recogida en la propuesta de resolución. En este supuesto, además el Tribunal Supremo confirma que no es necesario abrir una nueva fase de alegaciones del interesado, "exigencia que sólo procede cuando el órgano competente para resolver estima que la infracción resulta de mayor gravedad, más no cuando considera que procede una sanción distinta de la recogida en la propuesta de resolución pero en todo caso prevista por la Ley, como una de las varias aplicables a una misma clase de infracción, en este caso, grave".

La aplicación de la LDIEC al ámbito de las entidades de seguros y a quienes ejerzan cargos de administración o de dirección en las mismas, es tratado de forma detallada en la Sentencia del Tribunal Supremo de 17 de enero 2002 (TOL 129.600). La norma en virtud de la cual los administradores incurren en responsabilidad por las infracciones cometidas en una entidad aseguradora, al margen de la responsabilidad de ésta en cuanto tal, se encontraba ya en el artículo 44.1 de la Ley 33/1984, de 2 de agosto, sobre Ordenación del Seguro Privado, antes de su reforma por la Ley 26/1988 que, a este respecto, no hizo sino ratificar aquélla, en el aspecto mencionado, en el contenido de su Disposición Adicional Primera que afectó a la redacción de los artículos 43, 44 y 45 de la citada Ley 33/1984.

Con independencia de las sanciones que correspondan, el artículo 13 bis establece que las sanciones de multa e inhabilitación serán impuestas a determinados cargos de administración o de dirección que tienen mayor control y participación en las entidades, a los que se refiere el segundo párrafo del apartado 1 del artículo 1, participaciones significativas reguladas en el Título VI de esta Ley².

Como hemos comentado para las entidades, el abanico de sanciones que puede imponer la Resolución debe responder igualmente para los cargos de las mismas a una serie de criterios que la Ley establece para los mismos específicamente en el apartado 2 de su artículo 14, y que son los siguientes: a) El grado de responsabilidad en los hechos que concurra en el interesado. b) La conducta anterior del interesado, en la misma o en otra Entidad de crédito, en relación con las normas de ordenación y disciplina que le afecten, atendiendo a las sanciones firmes que le hubieran sido impuestas durante los últimos cinco años. c) El carácter de la representación que ostente el interesado.

22 Según establece el artículo 56 de la Ley, se entiende por participación significativa en una entidad de crédito española aquella que alcance, de forma directa o indirecta, al menos, un 10 por ciento del capital o de los derechos de voto de la entidad. Asimismo, tendrá dicha consideración aquella que, sin llegar al citado porcentaje, permita ejercer una influencia notable de la entidad. Reglamentariamente se determinará cuando se presume que una persona física o jurídica puede ejercer dicha influencia notable teniendo en cuenta, entre otras, la posibilidad de nombrar o destituir algún miembro de su consejo de administración. 
El artículo 17 de la Ley, ante la posibilidad que el número de los cargos sancionados con suspensión o separación impida la continuidad de la administración y dirección de la entidad de crédito, establece que la Resolución sancionadora podrá disponer el nombramiento provisional de los miembros necesarios con el fin que el órgano colegiado de administración pueda adoptar acuerdos, o bien el nombramiento provisional de uno o más administradores con la atribución de sus respectivas funciones.

Como disposiciones complementarias incluidas en el Título IV de la Ley, los artículos 40 y 41 se refieren específicamente a la responsabilidad sancionable en que incurren los miembros de las Comisiones de Control de las Cajas de Ahorro (cuestión de gran actualidad en los últimos meses y en la que sin embargo no se termina de producir la aplicación de sanciones a este tipo de Entidades de crédito y a sus cargos por razones políticas por todos conocidas con la manifiesta vulneración del principio de igualdad en la aplicación de la Ley que ello supone) así como los cargos y las Sociedades de Garantía Recíproca y Sociedades de Reafianzamiento23.

Por último, el artículo 16 de la Ley 26/1988 recoge la regulación relativa a las infracciones tipificadas en los artículos 4, 5 y 6 en relación con las obligaciones de los grupos consolidables de entidades de crédito y de los conglomerados financieros así como sus administradores y directivos. Para estos grupos, el apartado 2 de este artículo dispone que cuando la sanción deba ser la revocación de la autorización y la entidad financiera cabecera del grupo consolidado no tuviera la condición de entidad de crédito, se le impondrá entonces la sanción de disolución forzosa con apertura del período de liquidación. Sin embargo, en relación con estos grupos, dispone el apartado 3 del mismo que cuando proceda imponer las sanciones a personas físicas o a entidades que no ostenten la condición de entidades de crédito se aplicará en todo caso lo dispuesto en esta Ley 26/1988 para las entidades de crédito.

\section{Medidas de Intervención y Sustitución}

La LDIEC dedica su Título III a regular las Medidas de Intervención y de Sustitución cuya competencia corresponde al Banco de España y de cuya adopción debe dar cuenta razonada posteriormente al Ministro de Economía y Hacienda, de conformidad con lo dispuesto en su artículo 32. Estas medidas de intervención o sustitución

23 El artículo 40 relativo a los miembros de las comisiones de control de las Cajas de Ahorros establece un catálogo propio de infracciones muy graves, graves y leves (en este caso sí se establecen infracciones leves para estos cargos). Sin embargo, el apartado 4 del artículo 40 establece que las sanciones por la comisión de estas infracciones sí son las del régimen general de la Ley de los artículos 12 y 13, aunque con una reducción sustancial de la cuantía de las multas que sorprendentemente sólo serán de hasta 6.010 euros para las infracciones muy graves y hasta 3005 euros para las graves. Las leves serán sancionadas bien con amonestación privada bien con multa de hasta 300 euros. Por su parte, el artículo 41 establece que las Sociedades de Garantía Recíproca y Sociedades de Reafianzamiento y sus cargos que infrinjan normas de 284 ordenación o disciplina se someterán al régimen sancionador comentado regulado en el Título I de la Ley 
podrán adoptarse durante la tramitación de un expediente sancionador o con independencia del mismo.

Las medidas consisten en la intervención de la entidad de crédito o en la sustitución provisional de sus órganos de administración o dirección. Estas medidas únicamente pueden acordarse, de conformidad con lo dispuesto en el artículo 31, en dos supuestos reglados: a) cuando la entidad de crédito se encuentre en una situación de excepcional gravedad que ponga en peligro la efectividad de sus recursos propios o su estabilidad, liquidez o solvencia, o b) cuando existiendo indicios fundados del supuesto anterior de excepcional gravedad, no pueda deducirse de su contabilidad su verdadera situación.

El artículo 32.2 de la Ley recoge la iniciación a instancia de parte del expediente de estas medidas, cuya legitimación corresponde no sólo a los propios administradores de la entidad sino también al correspondiente órgano de fiscalización interna, así como a una minoría de socios que sea, al menos, igual al porcentaje exigido para instar la convocatoria de una Asamblea o una Junta General Extraordinaria. En relación con el procedimiento específico que conduce a la resolución definitiva, la Ley únicamente regula en su artículo 33 que la misma se adoptará previa audiencia de la entidad de crédito interesada durante el plazo que se establezca, que no podrá ser inferior a cinco días. Esta audiencia no será necesaria cuando las medidas se acuerden a petición de la entidad o cuando el retraso de la medida por dicho trámite comprometa gravemente la efectividad de la medida o los intereses económicos afectados. En este último supuesto, igualmente se establece, a diferencia del régimen general de recursos, que el plazo para la resolución del correspondiente recurso de alzada será tan sólo de diez días.

El acuerdo, según establece el artículo 34, designará la persona o personas que vayan a ejercer las funciones de intervención, o en su caso, hayan de actuar como administradores provisionales, debiendo concretar si deben actuar conjunta, mancomunada o solidariamente. El acuerdo tiene efectos inmediatamente ejecutivos, publicándose en el BOE y siendo objeto de inscripción en los registros públicos correspondientes, determinándose en dicha publicidad la eficacia del mismo frente a terceros. Como medio de ejecución forzosa de estos acuerdos, se establece expresamente la compulsión directa para la toma de posesión de las oficinas, libros y documentos, o para el exámen de estos últimos.

Los artículos 35 y 36 regulan respectivamente el supuesto de intervención y el caso de sustitución del órgano de administración. En los casos de intervención, a partir de la publicación del acuerdo en el BOE la validez de todos los actos y acuerdos de la entidad requieren la aprobación expresa de los interventores designados, excepto lógicamente las acciones legales o recursos contra la medida de intervención o la actuación de los interventores. Los interventores designados están facultados para revocar los poderes o delegaciones conferidos anteriormente por el órgano de administración o por sus apoderados, procediendo a la inscripción de su revocación en los registros públicos competentes. 
En los casos de sustitución del órgano de administración, por otra parte, los administradores provisionales tienen la consideración de interventores respecto de los actos y acuerdos de la Junta General o Asamblea de la entidad, siendo de aplicación lo dispuesto en el párrafo anterior en relación con la aprobación expresa por su parte de los actos y acuerdos de la entidad. A partir del momento en que el Banco de España acuerde el cese de la medida de intervención, los administradores provisionales convocarán la Junta General o Asamblea de la entidad con el fin de proceder al nombramiento del nuevo órgano de administración, de conformidad con lo dispuesto en el artículo 37 de la Ley. La obligación de formulación de las cuentas anuales de la entidad y de la gestión social, quedará en suspenso por un plazo no superior a un año si el nuevo órgano de administración estima que no cuenta con datos o documentos fiables y completos.

Por último, la Ley 6/2005 de 2 de abril dió una nueva redacción a los aspectos relativos al supuesto de disolución de una Entidad y liquidación por voluntad propia de la misma. El nuevo artículo 37 bis establece que la Entidad interesada deberá presentar al Banco de España la solicitud, quien fijará las condiciones de la misma en el plazo de tres meses desde su presentación. Y el artículo 38.1, por último, faculta al Ministro de Economía y Hacienda para que, en caso de disolución de una entidad de crédito, acuerde la intervención de las operaciones de liquidación de la misma en razón del número de afectados o de la situación patrimonial de la entidad. En estos casos, el artículo 38.2 extiende a dicho acuerdo lo dispuesto en el artículo 35 para los supuestos de intervención, y a los actos de los liquidadores y facultades de los interventores lo establecido en el artículo 36 que ya hemos comentado.

En relación con las medidas y facultades de sustitución, merece destacarse la Sentencia del Tribunal Supremo de 14 de marzo de 2006 (TOL 872.113) en relación con la conocida, por su gran repercusión pública, e importante, por la magnitud de la entidad bancaria, sustitución provisional del Consejo de Administración y de cualquier otro órgano de administración del Banco Español de Crédito. Este Acuerdo fue adoptado por el Consejo Ejecutivo del Banco de España con fecha 28 de diciembre de 1993, y confirmado por Resolución del Ministerio de Economía y Hacienda de fecha 9 de febrero de 1994 mediante la desestimación del recurso administrativo interpuesto frente al mismo. De esta importante y detallada Sentencia destacamos los siguientes aspectos:

a) La finalidad de las medidas de intervención y de sustitución y su regulación es independiente del ámbito sancionador. Su adopción está reservada, según el artículo 31 para el supuesto de que la entidad "se encuentre en una situación de excepcional gravedad que ponga en peligro la efectividad de sus recursos propios o su estabilidad, liquidez o solvencia". La finalidad de la medida es, por tanto, evitar que el peligro, que en ese momento es potencial, se transforme en real, con el consiguiente daño que ello supondría no sólo para la entidad y sus clientes, sino para todo el sistema fi286 vencia. Por ello, establece la Sentencia que: 
"No es, por tanto, una medida dirigida a reprobar una conducta supuestamente ilícita. Si además ésta existiera, la autoridad administrativa competente tiene otros medios a su alcance para perseguirla y castigarla. Se trata de una medida que aunque pueda guardar relación con el campo sancionador, como señala la Exposición de Motivos de la LDIEC, tiene su propia autonomía e independencia.... Partiendo de este carácter autónomo, caen por su base los argumentos de las partes recurrentes dirigidos a poner de manifiesto la ilegalidad de la sustitución de los administradores de Banesto por falta de cumplimiento de las garantías propias de los procedimientos sancionadores. La rigidez formal de estos procedimientos pretende ante todo salvaguardar el derecho de defensa del interesado, mientras que en el que se regula la intervención y sustitución en las entidades de crédito prima el interés general de que la economía no sufra quebranto como consecuencia del riesgo que ocasiona determinadas situaciones en que pueden caer estas entidades de crédito".

b) El artículo 33 de la Ley 26/1988 permite llevar a cabo la medida de sustitución sin la audiencia previa de la entidad de crédito "cuando el retraso que tal trámite origine comprometa gravemente la efectividad de la medida o los intereses económicos afectados".

El Tribunal Supremo rechaza los argumentos de los recurrentes relativos a: la ilegalidad de la sustitución prevista en el artículo 31, en tanto en cuanto su artículo 33 permite llevarla a cabo sin la audiencia previa de la entidad de crédito; la inconstitucionalidad por vulneración del derecho a la tutela judicial efectiva sin indefensión reconocido en el artículo 24 de la Constitución; y la vulneración de la Ley 30/1992 en relación con el requisito de audiencia en los procedimientos administrativos.

El Tribunal Supremo recuerda el contenido de la Exposición de Motivos de la propia Ley que establece la necesidad de someter las Entidades financieras a un régimen especial de supervisión administrativa, en general mucho más intenso que el que soporta la mayoría de los restantes sectores económicos. La captación de dinero de un gran número de personas sin los datos y los conocimientos necesarios para proceder a una evaluación propia de la solvencia de aquéllas obliga a ese régimen especial de regulación y supervisión públicas. Por todo ello, señala la Sentencia que:

"Este interés de protección del conjunto de la economía, al que se refiere la Exposición de Motivos, permite, en los supuestos excepcionales que se contemplan en el mencionado artículo 33, que queden subordinados al mismo otros intereses de tutela, que aunque también son dignos de protección, su respeto podría perjudicar aquel otro que se considera prevalente, máxime cuando a través del mecanismo de los recursos administrativos y jurisdiccionales, la posible indefensión y ausencia de contradicción que pudiera derivarse de la inicial falta de audiencia, quedarían subsanados en los procesos posteriores en los que los interesados pueden hacer efectivo su derecho de defensa".

Y, a continuación, señala que la LDIEC al permitir en estos supuestos la no audiencia de la Entidad de Crédito no vulnera ni entra en contradicción con la Ley 30/1992 ya que: 
"en relación con el trámite de audiencia, la $\angle P A C$ es especialmente restrictiva en relación con informaciones y datos relativos a actuaciones administrativas derivadas de la política monetaria, como se infiere de sus artículos 84.1 y 37.5.e). En un procedimiento como es el de medidas de intervención o sustitución en las entidades de crédito, no hay duda que el sector de la economía, como se dijo, se encuentra en juego, y las informaciones y datos que en el procedimiento se barajen serán exclusivamente de este orden, con lo que el trámite de audiencia puede ser omitido, según se infiere de las previsiones de la $L P A C$. Por otra parte, la urgencia que puede exigir la adopción de la sustitución determina la superación que de este trámite ha sido reconocido por la jurisprudencia recaída en las sentencias de esta Sala de 23 de febrero de 1998 y 9 de abril de 1999, que, aunque referidas a la ejecución de obras o actividades sin licencia o en contra de la misma, mantienen el criterio de permitir la adopción de la medida de suspensión sin necesidad de una previa audiencia".

c) Otro aspecto al que se da especial énfasis por parte de los recurrentes es el relativo a la realidad del presupuesto de hecho que establece el artículo 31 de la Ley, que se pone en duda por los mismos, y que es el único posible que otorgaría validez a la sustitución de los administradores. El art. 31 de la LDIEC establece, como requisito para la aplicación de la medida, que la entidad de crédito "se encuentre en una situación de excepcional gravedad”, pero no de cualquier tipo de gravedad, sino específicamente en aquella que "ponga en peligro la efectividad de sus recursos propios o su estabilidad, liquidez o solvencia”. La Sentencia resume la siguiente situación financiera en la que se encontraba la Entidad Bancaria y que justifica la medida adoptada por constituir hechos que generan el peligro que señala la Ley:

"La existencia de un déficit de fondos especiales y unos activos ficticios cifrados en 341.076 millones de pesetas, la notoria insuficiencia de los recursos propios para el volumen y características de la actividad del grupo Banesto que requieren unos ajustes al menos de 455.000 millones de pesetas, el aumento de forma notable de la concentración de riesgos superior al legal del $40 \%$ de los recursos propios, la acentuada debilidad en la generación de recursos y los importantes saneamientos pendientes, que son los elementos en los que se basa el acuerdo del Consejo Ejecutivo del Banco de España, son hechos que generan el peligro que señala la norma, y que podrían producir, si no se adopta la medida, cualquiera de las situaciones de inestabilidad, iliquidez $o$ insolvencia, con el daño que esto supone para los depositantes y acreedores de la entidad, para el sistema general de pagos, para el sector financiero y para la economía en su conjunto" 24 .

24 La Sentencia del Tribunal Supremo recuerda que en casación no se contempla el error de hecho en la apreciación de la prueba, "por lo que apreciando en conjunto las pruebas practicadas en el Tribunal de instancia, que llegó a la conclusión de que se daba el supuesto excepcional que contempla el artículo 31 de la Ley de Disciplina e Intervención de las Entidades de Crédito, no considera la Sala que la misma sea arbitraria ni errónea-únicos supuestos en los que cabría en esta casación rectificar la valoración de la prueba hecha en la sentencia recurrida-, porque se base en informes y datos emitidos por personas cualificadas cuya imparcialidad, pese a las manifestaciones de subjetividad hechas por las partes, no puede ponerse en duda sin una prueba irrefutable en contra. También hay que resaltar, frente a algunas manifestaciones de las partes, que no es preciso que ya se esté en situación de insolvencia, iliquidez, inestabilidad o ineficiencia de sus recursos propios, sino que basta que haya un peligro evidente de que se produzcan, no necesariamente todas estas situaciones, sino cualquiera de ellas, como claramente se desprende de la conjunción disyuntiva que usa la norma, 
d) La autoridad supervisora, el Banco de España, tiene discrecionalidad técnica para de conformidad con el artículo 33 de la Ley decidir si acuerda bien la intervención de la Entidad o bien la sustitución de los administradores de acuerdo con la mejor garantía de los intereses generales: "El que se haya acudido a la sustitución de los administradores y no a la intervención de la entidad, conforme a la elección que permite el art. 33 de la LDIEC, es una cuestión que no puede ser discutida, pues salvo en supuestos de arbitrariedad que aquí no se aprecian, es la discrecionalidad técnica de la Administración la que debe decidir cual es la que satisface mejor los intereses generales. En este punto deben darse por reproducidos los razonamientos de la sentencia recurrida, que se aceptan en lo relativo a la eficacia, coordinación y proporcionalidad del acto impugnado".

e) El carácter provisional de la medida adoptada de sustitución implica que el régimen ordinario de administración sea sustituido por medidas extraordinarias, en el que, frente a las alegaciones de los recurrentes, las reglas generales de aplicación a la administración de las sociedades anónimas no tienen virtualidad propia.

Alegan los recurrentes infracción de los siguientes preceptos mercantiles: art. 123 de la Ley de Sociedades Anónimas al no respetarse el número mínimo de administradores, ni las condiciones exigibles para ser nombrado administrador (art. 15 y 19 de los Estatutos de Banesto), art. 132.2 de la LSA y 1 de la Ley 31/68, por incompatibilidades bancarias, art. 136 de la LSA por confiar la administración conjuntamente a mas de dos personas sin constituir Consejo de Administración, art. 141 de la LSA por designar directamente el Presidente del órgano citado, que es competencia exclusiva del propio Consejo de Administración, no debió distinguirse entre administradores provisionales y ordinarios. Señalan que estas infracciones no pueden justificarse en el carácter excepcional de la medida pues el art. 34.1 de la LDIEC debe ser aplicado de modo que no contradiga la LSA.

La Sentencia de 14 de marzo de 2006, que estamos comentando, establece que la no existencia de contradicción de esta Ley con la Ley de Sociedades Anónimas se fundamenta en los propios preceptos de la Ley de Disciplina e Intervención de las Entidades de Crédito que se aparta del régimen de estas sociedades durante la vigencia de la medida,

"como lo demuestra que permita la designación de una sola persona como adminis-
trador provisional, la posibilidad de que los administradores provisionales actúen con-
junta, mancomunada o solidariamente, la suspensión de las obligaciones de formular
las cuentas anuales y la aprobación de éstas y de la gestión social, facultad para sus-
pender los acuerdos de la Junta General. Debe tenerse en cuenta que el artículo 3 de la
Ley de Sociedades Anónimas está admitiendo la posibilidad de que estas entidades se
rijan por disposiciones que les sean especificamente aplicables, como es el caso de la

por lo que resulta indiferente que algunas pérdidas, como señala uno de los recurrentes, sean reversibles, si basta la mera inestabilidad de la entidad, para que la medida pueda ser acordada". 
LDIEC en el punto que aquí se examina. Además las designaciones se hacen a título personal, desvinculándolas de su procedencia, de tal forma que las posibles incompatibilidades, caso de existir, habrían desaparecido desde el momento en que los designados se encuentran en situación de cese transitorio en sus entidades de origen".

f) Por último, igualmente destacamos que la medida adoptada de sustitución nada tiene que ver con una expropiación, como manifiestan los recurrentes en sospechosa alegación que demuestra el carácter patrimonial con el que, en muchos casos, se terminan manejando y dirigiendo las grandes Sociedades y Entidades por parte de sus Consejos de administración de forma muy alejada de los Códigos de buenas prácticas y del respeto de los accionistas que son los verdaderos y únicos titulares y propietarios de las mismas.

Así, establece la Sentencia que "debe rechazarse también la alegación de que con el acuerdo recurrido lo que se ha pretendido es una expropiación sin indemnización, pues, al margen de la utilidad pública que tiene la medida de sustitución, único elemento de similitud con la expropiación, falta el más esencial de esta institución, cual es el de privar a los accionistas, verdaderos titulares de la entidad, de sus derechos en beneficio de otros, cosa que no ha ocurrido". 